\title{
Pro-Brain-Derived Neurotrophic Factor Inhibits GABAergic Neurotransmission by Activating Endocytosis and Repression of $\mathrm{GABA}_{\mathrm{A}}$ Receptors
}

\author{
Baptiste Riffault, Igor Medina, 1 Camille Dumon, Carine Thalman, Nadine Ferrand, Perrine Friedel, Jean-Luc Gaiarsa, \\ and $\odot$ Christophe Porcher \\ Aix-Marseille Université, Institut National de la Santé et de la Recherche Médicale Unité 901, and Institut de Neurobiologie de la Méditerranée, Parc \\ Scientifique de Luminy, 13273 Marseille, France
}

GABA is the canonical inhibitory neurotransmitter in the CNS. This inhibitory action is largely mediated by GABA type A receptors $\left(\mathrm{GABA}_{\mathrm{A}} \mathrm{Rs}\right)$. Among the many factors controlling GABAergic transmission, brain-derived neurotrophic factor (BDNF) appears to play a major role in regulating synaptic inhibition. Recent findings have demonstrated that BDNF can be released as a precursor (proBDNF). Although the role of mature BDNF on GABAergic synaptogenesis and maintenance has been well studied, an important question still unanswered is whether secreted proBDNF might affect GABAergic neurotransmission. Here, we have used $14 \mathrm{~d}$ in vitro primary culture of hippocampal neurons and ex vivo preparations from rats to study the function of proBDNF in regulation of $\mathrm{GABA}_{\mathrm{A}} \mathrm{R}$ trafficking and activity. We demonstrate that proBDNF impairs GABAergic transmission by the activation of two distinct pathways: (1) a RhoA-RockPTEN pathway that decreases the phosphorylation levels of $\mathrm{GABA}_{\mathrm{A}} \mathrm{R}$, thus affecting receptor function and triggering endocytosis and degradation of internalized receptors, and (2) a JAK-STAT-ICER pathway leading to the repression of $\mathrm{GABA}_{\mathrm{A}} \mathrm{Rs}$ synthesis. These effects lead to the diminution of GABAergic synapses and are correlated with a decrease in GABAergic synaptic currents. These results revealed new functions for proBDNF-p75 neurotrophin receptor signaling pathway in the control of the efficacy of GABAergic synaptic activity by regulating the trafficking and synthesis of $\mathrm{GABA}_{\mathrm{A}} \mathrm{Rs}$ at inhibitory synapses.

Key words: BDNF; $\mathrm{GABA}_{\mathrm{A}}$ receptors; intracellular trafficking; synaptic plasticity

\section{Introduction}

In the mature nervous system, the inhibitory action of GABA neurotransmitter is primarily mediated through GABA type A receptors $\left(\mathrm{GABA}_{\mathrm{A}} \mathrm{Rs}\right)$. It has been reported that altered expression and function of $\mathrm{GABA}_{\mathrm{A}}$ Rs may contribute to major pathological conditions, including neurodegenerative diseases (Twelvetrees et al., 2010), cognitive disorders, addiction ( $\mathrm{Ru}-$ dolph and Knoflach, 2011), and epilepsies (Ben-Ari et al., 2007), and to pharmacoresistance to benzodiazepines in epileptic patients (Tan et al., 2011). Additionally, enhancement of the inhibitory action of $\mathrm{GABA}_{\mathrm{A}}$ Rs has been widely used clinically for treatment of numerous neurological disorders, such as anxiety,

\footnotetext{
Received May 21, 2014; revised Aug. 1, 2014; accepted Aug. 28, 2014.

Author contributions: J.-L.G. and C.P. designed research; B.R., I.M., C.D., C.T., N.F., P.F., and C.P. performed research; B.R. and C.D. analyzed data; B.R., J.-L.G., and C.P. wrote the paper.

This work was supported by The National Institute of Health and Medical Research, the National Center for Scientific Research, and the National Agency for Research (Grant R07066AS 2008-2011). Confocal microscopy was performed at the imaging platform InMAGIC of the Institut de Neurobiologie de la Méditerranée (INSERMU901). We give special to Christophe Pellegrino for assistance in Western blotting, to François Michel for help with confocal microscopy, to Diabe Diabira for electrophysiology, and to the Tous Chercheurs Association for help with ELISA assays. We also thank Franck Chazal for critical reading of the manuscript.

The authors declare no competing financial interests.

Correspondence should be addressed to Christophe Porcher, INMED, INSERM U901, Parc scientifique de Luminy, BP 13, 13273 Marseille Cedex 09, France. E-mail: Christophe.porcher@inserm.fr.

DOI:10.1523/JNEUROSCI.2069-14.2014

Copyright $\odot 2014$ the authors $\quad 0270-6474 / 14 / 3413516-19 \$ 15.00 / 0$
}

insomnia, agitation, seizures, muscle spasms, and alcohol withdrawal (Winsky-Sommerer, 2009; Rudolph and Knoflach, 2011; Tan et al., 2011; Skolnick, 2012). Therefore, understanding the mechanisms involved in regulation of cell-surface expression of $\mathrm{GABA}_{\mathrm{A}} \mathrm{Rs}$ is of primary importance for both fundamental research and clinical application.

Among the many dependent regulators of the GABAergic system, brain-derived neurotrophic factor (BDNF) is of particular interest as it is released in response to GABAergic activity (Elmariah et al., 2004; Jovanovic et al., 2004; Carrasco et al., 2007; Porcher et al., 2011). In cultured hippocampal neurons, acute application of BDNF increases the cell-surface expression of $\mathrm{GABA}_{\mathrm{A}} \mathrm{Rs}$ and enhances GABAergic synaptic transmission (Jovanovic et al., 2004; Porcher et al., 2011). In the hippocampal neuronal network, chronic release of BDNF enhances the formation and functional maturation of GABAergic synapses (Gubellini et al., 2005; Kuczewski et al., 2008b; Fiorentino et al., 2009). BDNF is expressed mainly by glutamatergic neurons and secreted through a regulated and constitutive pathway (Haubensak et al., 1998; Wu et al., 2004; Kuczewski et al., 2008a; Lessmann and Brigadski, 2009). BDNF is stored as proneurotrophin (proBDNF) within secretion vesicles ( $\mathrm{Lu}, 2003)$. To produce mature BDNF ( $\mathrm{mBDNF}$ ), proBDNF is cleaved by furin in the trans-Golgi network (Mowla et al., 2001), or by extracellular plasmin or matrixmetalloprotease-7 once secreted (Lee et al., 
2001). The proteolysis of proBDNF is regulated by neuronal activity that in turn determines the extracellular ratio between mBDNF and proBDNF (Lessmann and Brigadski, 2009; Nagappan et al., 2009; Yang et al., 2009). ProBDNF and mBDNF are assumed to produce opposing physiological responses mediated by the activation of two distinct classes of transmembrane receptors, the tropomyosin-related kinase receptor B $(\mathrm{TrkB})$ and the p75 neurotrophin receptor (p75 ${ }^{\mathrm{NTR}}$; Lee et al., 2001; Lu et al., 2005). Thus, the physiological action of BDNF is regulated by proteolytic cleavage, with proBDNF preferentially activating p75 ${ }^{\text {NTR }}$ and mBDNF activating TrkB. Moreover, while the contribution of the mBDNF-TrkB signaling pathway to the development and maturation of GABAergic synapses is well established (Lessmann and Brigadski, 2009; Kuczewski et al., 2010), the questions of whether and how proBDNF/p $75^{\text {NTR }}$ signaling affects GABAergic synapses are largely unanswered.

In this study we sought to examine the role of the proBDNF/ p $75^{\text {NTR }}$ signaling pathway in regulating GABAergic synaptic transmission by investigating $\mathrm{GABA}_{\mathrm{A}} \mathrm{R} \beta_{2 / 3}$ subunit cell-surface stability, membrane trafficking, and GABAergic synaptic currents in primary culture of hippocampal neurons and acute hippocampal slices. Our results provide the first compelling evidence that proBDNF downregulates $\mathrm{GABA}_{\mathrm{A}} \mathrm{R} \beta_{2 / 3}$ subunit surface expression through an increase in internalization and a decrease in synthesis.

\section{Materials and Methods}

All animal experiments were performed according to the guidelines set by the Institut National de la Santé et de la Recherche Médicale animal welfare committee and the European Community Council Directive of November 24, 1986 (86/609/EEC).

Primary cultures of rat hippocampal neurons. Hippocampal neurons from 18-d-old Wistar rat embryos were dissociated using trypsin and plated onto poly-ethylenimine-coated coverslips at a density of 70,000 cells per square centimeter in minimal essential medium (MEM) supplemented with 10\% NU-Serum (BD Biosciences), 0.45\% glucose, $1 \mathrm{~mm}$ sodium pyruvate, $2 \mathrm{~mm}$ glutamine, and $10 \mathrm{IU} \mathrm{ml}^{-1}$ penicillin-streptomycin as previously described (Buerli et al., 2007). On days 10 and 13 of culture incubation, half of the medium was changed to MEM with 2\% B27 supplement (Life Technologies).

Reagents and treatments. Primary hippocampal neuronal cultures (14 DIV) were treated with the following concentration of blockers and inhibitors, before being treated with an acute application of mBDNF or cleavage resistant proBDNF (CR-proBDNF): tetrodotoxine (TTX; $0.5 \mu \mathrm{M}, 1 \mathrm{~h}), 2,3$-dihydroxy-6-nitro-7-sulfonyl-benzo[f] quinoxaline (NBQX; $5 \mu \mathrm{M}, 10 \mathrm{~min}$ ), D-APV (40 $\mu \mathrm{M}, 10 \mathrm{~min}$ ). Cultures were then stimulated with CR-proBDNF ( $25 \mathrm{ng}, 30 \mathrm{~min}$ ) in the presence or absence of $\mathrm{mBDNF}$ ( $25 \mathrm{ng}, 10 \mathrm{~min}$ ). For sustained stimulation with endogenous proBDNF, cultures were treated with aprotinin $(3 \mu \mathrm{g} / \mathrm{ml})$ alone. In some experiments, cultures were incubated for $\geq 40 \mathrm{~min}$ before stimulation with K252a (200 nм), TAT-pep5 (2 $\mu \mathrm{M})$, nifedipine (10 $\mu \mathrm{M})$, leupeptine $(5 \mu \mathrm{g} / \mathrm{ml})$, AG490 $(50 \mu \mathrm{M})$, ROCK (Rho-associated, coiled-coil containing protein kinase) inhibitor (ROCKi; $50 \mu \mathrm{M})$ or Stattic $(10 \mu \mathrm{M})$. All reagents were applied directly from stock solutions into culture medium or artificial CSF (ACSF) for electrophysiological experiments.

ProBDNF immunoassay. To measure the release of proBDNF from hippocampal neuronal cultures, $2 \mathrm{ml}$ fractions of the supernatant were collected. The fractions were concentrated using the Amicon Ultra concentration devices $(4000 \times g, 10 \mathrm{~min}$; Millipore), with $100 \mu \mathrm{l}$ of final volume. The proBDNF Rapid ELISA Kit (Biosensis) was used to quantify the amount of proBDNF in the concentrated solutions following the manufacturer's protocol. Experiments and analysis were done blind.

Transfections. Transfections of 10 DIV neuronal cultures were performed as described previously (Buerli et al., 2007). For transfection of cultures in $35 \mathrm{~mm}$ dishes, $300 \mu$ l of Opti-MEM media were mixed with 7 $\mu \mathrm{l}$ of Lipofectamine 2000 reagent (Life Technologies), $1 \mu$ l of Magneto- fection CombiMag (OZ Biosciences), and $1.5 \mu \mathrm{g}$ of pcDNAs. The mixture was incubated $15 \mathrm{~min}$ at room temperature (RT) and thereafter distributed dropwise above the neuronal culture. Culture dishes were placed on a magnetic plate (OZ Biosciences) and incubated $45 \mathrm{~min}$ at $37^{\circ} \mathrm{C}$. Transfection was terminated by the substitution of $80 \%$ of the incubation solution with fresh culture media. Neurons were used in experiments $4 \mathrm{~d}$ after transfection.

Electrophysiological recordings of mIPSCs on neuronal cultures. Electrophysiological recordings from neurons were performed at 14 DIV (4 d after transfection). At this age, cultured neurons achieved a developmental stage characterized by the steady-state level of the expression of $\mathrm{GABA}_{\mathrm{A}}$ Rs (Swanwick et al., 2006), the slowing of dendrite growth, and the beginning of spine formation (Huang et al., 2005). Neurons were continuously perfused with an extracellular solution containing the following (in mM): $150 \mathrm{NaCl}, 2.5 \mathrm{KCl}, 2.5 \mathrm{HEPES}, 20 \mathrm{D}$-glucose, $2.0 \mathrm{CaCl}_{2}$, $2.0 \mathrm{MgCl}_{2}, 0.001 \mathrm{TTX}, 0.01 \mathrm{CNQX}, \mathrm{pH} 7.4$, at $1 \mathrm{ml} / \mathrm{min}$. Recording electrodes $(4-6 \mathrm{M} \Omega$ ) were filled with a solution containing the following (in mM): $140 \mathrm{CsCl}, 10 \mathrm{HEPES}, 2.5 \mathrm{MgCl}_{2}, 4 \mathrm{Na}_{2}$-ATP (adenosine triphosphate), $0.4 \mathrm{Na}$-GTP (guanosine triphosphate), $10 \mathrm{~mm}$ sodium phosphocreatine, $0.6 \mathrm{~mm}$ EGTA, pH 7.2. Recordings were made using an Axopatch-200A amplifier and pCLAMP acquisition software (Molecular Devices). Series resistance was compensated electronically. Data were low-pass filtered at $2 \mathrm{kHz}$ and acquired at $10 \mathrm{kHz}$. Miniature postsynaptic currents were analyzed blindly using Mini Analysis software (Synaptosoft). All experiments were performed at $22-24^{\circ} \mathrm{C}$. Cumulative distributions were generated using 100 consecutive mIPSCs, averaged across all cells.

Western blotting. Neuronal cells and hippocampi were homogenized in RIPA buffer (150 mm NaCl, 1\% Triton X-100, 0.1\% SDS, 50 mм Tris $\mathrm{HCl}, \mathrm{pH} 8$, containing protease inhibitors (Complete Mini, Roche). Lysates were centrifuged $\left(10,000 \times g\right.$ for $10 \mathrm{~min}$ at $\left.4^{\circ} \mathrm{C}\right)$ and the supernatant was heated at $90^{\circ} \mathrm{C}$ for $5 \mathrm{~min}$ with Laemmli loading buffer. Loading was $20 \mu \mathrm{g}$ of proteins as determined using a modified Bradford reaction (Bio-Rad Laboratories). Proteins were separated in 7-15\% SDS-PAGE and electrophoretically transferred to nitrocellulose membranes. Membranes were blocked with $5 \%$ bovine serum albumin (BSA) in TBS $0.1 \%$ Tween 20 (TBST) for $2 \mathrm{~h}$ at RT, then incubated with primary antibodies diluted in TBST containing $3 \%$ BSA overnight at $4^{\circ} \mathrm{C}$ or $2 \mathrm{~h}$ at RT. Blots were probed with antibody against phospho- $\mathrm{GABA}_{\mathrm{A}} \mathrm{R} \beta_{3}\left(\mathrm{pGABA}_{\mathrm{A}} \mathrm{R} \beta_{3}\right.$, rabbit, Ser408/409, PhosphoSolutions), GABA $\mathrm{R} \beta_{3}$ (mouse, Millipore Bioscience Research Reagents), EEA1 (early endosome antigen 1; rabbit; Cell Signaling Technology), inducible cAMP early repressor (ICER; Crem1, rabbit; Santa Cruz Biotechnology), p75 ${ }^{\text {NTR }}$ (mouse; Biosensis), tubulin ( $\beta$-tubulin; mouse; Sigma-Aldrich), PTEN (phosphatase and tensin homolog on chromosome 10; mouse; Millipore), and phosphoPTEN (pPTEN; rabbit T366, Abcam). After washing with TBST, membranes were incubated with HRP-conjugated secondary antibodies diluted in TBST containing 3\% BSA for $60 \mathrm{~min}$, washed with TBST, and then developed using the G:BOX gel imaging system (Syngene). Expression levels were estimated by ImageJ software (National Institutes of Health, http://rsb.info.nih.gov/ij/).

Immunocytochemistry and confocal microscopy. Hippocampal cultures $\left(75,000\right.$ cells $/ \mathrm{cm}^{2}$, DIV 14) were treated as described above and fixed in $4 \%$ PFA-sucrose for $10 \mathrm{~min}$. Coverslips were washed in PBS for $15 \mathrm{~min}$ and incubated in $0.2 \mathrm{~m}$ glycine for $10 \mathrm{~min}$. Blocking was done in $1 \%$ BSA $/ 0.5 \%$ Triton X-100 in PBS for 30 min to permeabilize cells and reduce nonspecific binding. Cultures were washed and incubated with goat anti-p $75^{\text {NTR }}$ (1:500; R\&D Systems) or rabbit anti-caspase- 3 cleaved (1:500; Cell Signaling Technology) or rabbit anti-EEA1 (1:500; Cell Signaling Technology) and anti- $\beta_{2 / 3}$ antibody (1:200; clone bd17; Millipore) coupled to chicken anti-MAP2 (anti-microtubule-associated protein 2; 1:2000; Sigma-Aldrich) antibodies in PBS overnight at $4^{\circ} \mathrm{C}$. For analysis of cell-surface $\mathrm{GABA}_{\mathrm{A}}$ Rs and GABAergic synapses, nonpermeabilized neurons were first incubated with anti- $\beta_{2 / 3}$ antibody (1:200; clone bd17; Millipore) overnight at $4^{\circ} \mathrm{C}$. Coverslips were washed in PBS for $15 \mathrm{~min}$ and permeabilized in $0.5 \%$ Triton-1\% BSA in PBS for $10 \mathrm{~min}$. Neurons were then incubated with primary antibodies using rabbit antiVAMP1 (vesicle-associated membrane protein 1; 1:2000; Synaptic Systems) and donkey anti-MAP2 (1:2000; Sigma-Aldrich) for $2 \mathrm{~h}$ at RT. 
Primary antibodies were visualized after staining with the appropriate goat anti-mouse, anti-rabbit, and anti-donkey IgG conjugated to Alexa488 (1:1000; FluoProbes), Alexa555 (1:1000; FluoProbes), and Cy5, respectively (1:2000, Millipore Bioscience Research Reagents), in 1\% BSA/PBS for $60 \mathrm{~min}$. Cultures were washed and coverslips mounted using Vectashield (Vector). Sequential acquisition of immunoreactivity of pyramidal-like cells was performed using laser scanning confocal microscope (Zeiss LSM 510 Meta) with a $40 \times$ or $63 \times$ oil-immersion objectives. In each set of images, laser light levels and detector gain and offset were adjusted to avoid any saturated levels. Confocal micrographs are digital composites of a $Z$-series scan of $4-6$ optical sections through a depth of $4-5 \mu \mathrm{m}$.

Immunofluorescence analysis. For each experimental condition, the density, area, and colocalization of puncta were determined from confocal images using the ImageJ software. Immunopositive puncta were defined as immunoreactivity $>0.1 \mu \mathrm{m}^{2}$ present along the soma and the first $20 \mu \mathrm{m}$ length of the primary process. For $\mathrm{GABA}_{\mathrm{A}} \mathrm{R} \beta_{2 / 3}$ cell-surface expression, the labeled area fraction of positive pixels for GABA $\mathrm{R} \beta_{2 / 3}$ was measured and reported to the area fraction of positive pixels for MAP2. Colocalization was analyzed by determining the percentage of individual $\beta_{2 / 3}$ subunit-positive puncta that were in close apposition to VAMP1 immunoreactive puncta. This value was divided by the area fraction of positive pixels for MAP2. All of the images were analyzed blindly.

Phospho-cAMP response element-binding protein activation. The procedure for phospho- cAMP response element-binding protein (phosphoCREB) activation and immunocytochemistry was similar to that described previously (Kuczewski et al., 2008a). Cultures were stimulated with CR-proBDNF (30 min) in the absence or presence of mBDNF (10 $\mathrm{min}$ ) with or without K252a. Thirty minutes after stimulation, neurons were fixed for $10 \mathrm{~min}$ with PFA-sucrose at $4^{\circ} \mathrm{C}$ and rinsed several times with PBS. Coverslips were then preincubated in $0.1 \%$ Triton, $3 \%$ goat serum, and PBS for $60 \mathrm{~min}$ at RT and incubated overnight with mouse anti-CREB (1:1000), rabbit anti-phospho-CREB (anti-pCREB; 1:1000; both from Cell Signaling Technology), and chicken anti-MAP2 (1:2000; Sigma-Aldrich) antibodies. Immunoreactivities for pCREB, CREB, and MAP2 were visualized and analyzed as described above using the laser scanning confocal microscope (Zeiss LSM 510 Meta). The optical sections were digitized $(1024 \times 1024$ pixels $)$ and processed using ImageJ software. For analysis of the intensity of pCREB staining in neuronal cells, we first created a binary mask from MAP2-positive cells and then analyzed pCREB intensity only in regions overlapping the binary mask. Acquisition parameters were the same for every set of experiments. The pCREB-to-CREB intensity ratio was expressed as the mean ratio of the pCREB-Alexa Fluor 488/CREB-Alexa Fluor 555 staining intensity. All data were expressed as percentage of control values obtained from sister nonstimulated cultures. All of the images were analyzed blindly.

ICER activation. Cultures (14 DIV) were stimulated overnight with aprotinin $(12 \mathrm{~h})$ or treated with CR-proBDNF $(30 \mathrm{~min})$ as described above, in the absence or presence of TAT-pep5. After stimulation, neurons were treated as previously described and incubated overnight with rabbit anti-CREM1 (1:100; ICER; Santa Cruz Biotechnology) and chicken anti-MAP2 (1:2000; Sigma-Aldrich) antibodies. Immunoreactivities for ICER and MAP2 were visualized and analyzed as described above. The intensity of ICER staining in neuronal cells was expressed as the mean ratio of the ICER-Alexa Fluor 555/MAP2-Alexa Fluor 488 staining intensity. All data were expressed as percentage of control values obtained from sister nonstimulated cultures. All of the images were analyzed blindly.

Determination of $G A B A_{A} R$ cell-surface levels using ELISA. Changes in surface and total levels of $\mathrm{GABA}_{\mathrm{A}}$ Rs were analyzed using a cell-surface ELISA assay as described previously (Jovanovic et al., 2004; Porcher et al., 2011). Hippocampal neurons were cultured in 24 -well plates at a density of $100,000 \mathrm{cells} / \mathrm{cm}^{2}$ for 14 DIV. Cultures were treated as described above and fixed using 4\% PFA/4\% sucrose/PBS (4\% PFA-sucrose) for $10 \mathrm{~min}$. Cultures were washed with PBS followed by HBSS (Invitrogen). Nonspecific cell-surface binding of antibody was reduced by incubating cultures for $30 \mathrm{~min}$ in $1 \% \mathrm{BSA} / 10 \%$ rabbit serum/HBSS. In those cultures where total protein levels were evaluated, cells were permeabilized and nonspe- cific binding blocked by incubating with $0.5 \%$ Triton/ $1 \%$ BSA $/ 10 \%$ rabbit serum/HBSS for $30 \mathrm{~min}$. Cultures were incubated with anti-GABA $\mathrm{A}_{\mathrm{A}} \mathrm{R}$ $\beta_{2 / 3}$ antibody ( $2 \mu \mathrm{g} / \mathrm{ml}$; bd17 clone; Millipore) overnight at $4^{\circ} \mathrm{C}$. After washing and nonspecific binding block as described above, cultures were incubated with anti-mouse IgG conjugated to HRP (1:5000, Pierce) for $60 \mathrm{~min}$. Cultures were extensively washed and a color substrate 3,3,5,5tetramethylbenzidine (Sigma-Aldrich) reagent added for $15 \mathrm{~min}$ until sufficient color reaction had developed. Absorbances were read at $\lambda=$ $655 \mathrm{~nm}$ using a spectrophotometer (Fluostar Optima, BMG Labtech). Controls lacking the primary antibody were routinely used to determine background levels of peroxidase and nonspecific binding of the secondary antibody.

Relative quantitative expression of $m R N A$ transcripts. Hippocampal neuronal cultures were treated as described above. At 14 DIV, RNA was isolated using a Qiagen RNeasy kit following the manufacturer's instructions, quantified by reading the absorbance at $260 \mathrm{~nm}$ (NanoPhotometer, Implen), and converted to cDNA using $1 \mu \mathrm{g}$ of RNA according to manufacturer's instructions (QuantiTect Reverse Transcription kit, Qiagen). PCR was performed with the LightCycler 480 SYBR Green I Master (Roche Applied Science) with $1 \mu \mathrm{l}$ of cDNA using the following oligonucleotides (QuantiTect Primer Assays; Qiagen): $\mathrm{GABA}_{\mathrm{A}} \mathrm{R} \beta_{3}$ subunit ( $\mathrm{Ga}$ brb3; QT00195902), cAMP responsive element modulator 1 (Crem1; QT00370370), p75 ${ }^{\text {NTR }}$ (Ngfr; QT00181874), and glyceraldehyde-3phosphate dehydrogenase (GAPDH; QT001199633). Relative mRNA values were calculated using the LC480 software by using GAPDH as the housekeeping gene. PCR was performed in replicates of three.

In vivo injection. Before intracerebroventricular injection, the rats of either sex were anesthetized at birth by $3 \%$ isoflurane mixed with pure oxygen and placed in a stereotaxic frame. Tissue-type plasminogen activator-Stop (tPA-Stop) was dissolved at $6 \mathrm{~nm}$ in $0.9 \%$ sodium chloride. A Hamilton syringe was inserted $3 \mathrm{~mm}$ deep, perpendicular to the skull surface and $5 \mathrm{~mm}$ rostral and $3 \mathrm{~mm}$ lateral from the lambda. Intracerebroventricular injection $(3 \mu \mathrm{l})$ was administered over $60 \mathrm{~s}$. The needle was kept immobilized for 2 min before withdraw. Control animals received PBS with $0.4 \%$ BSA. The validity of injection was determined by using blue dye dissolved in the injected solution. After the injection, the animals were left for $48 \mathrm{~h}$ before starting electrophysiological recordings.

Slices preparation. Electrophysiological recordings from hippocampal slices were performed from 2-d-old rats (i.e., $2 \mathrm{~d}$ after intracerebroventricular injections of tPA-Stop) as previously described (Kuczewski et al., $2008 \mathrm{~b})$. Brains were removed and immersed into ice-cold $\left(2-4^{\circ} \mathrm{C}\right) \mathrm{ACSF}$ with the following composition (in $\mathrm{mm}$ ): $126 \mathrm{NaCl}, 3.5 \mathrm{KCl}, 2 \mathrm{CaCl}_{2}, 1.3$ $\mathrm{MgCl}_{2}, 1.2 \mathrm{NaH}_{2} \mathrm{PO}_{4}, 25 \mathrm{NaHCO}_{3}$, and 11 glucose, $\mathrm{pH}$ 7.4, equilibrated with $95 \% \mathrm{O}_{2}$ and $5 \% \mathrm{CO}_{2}$. Hippocampal slices ( $600 \mu \mathrm{m}$ thick) were cut with a McIlwain tissue chopper and kept in ACSF at RT $\left(25^{\circ} \mathrm{C}\right)$ for $\geq 1 \mathrm{~h}$ before recording. Slices were then transferred to a submerged recording chamber perfused with $\mathrm{ACSF}(3 \mathrm{ml} / \mathrm{min})$ at $34^{\circ} \mathrm{C}$.

Electrophysiological recording on hippocampal slices. Whole-cell patchclamp recordings of CA3 pyramidal neurons were performed with an Axopatch 200B amplifier (Molecular Devices). Microelectrodes (4-8 $\mathrm{M} \Omega$ ) were filled with a recording solution with the following composition (in mM): $110 \mathrm{CsCl}, 30 \mathrm{~K}$-gluconate, $10 \mathrm{HEPES}, 1.1 \mathrm{EGTA}, 0.1 \mathrm{CaCl}_{2}$, $4 \mathrm{MgATP}$, and $0.3 \mathrm{NaGTP}$. Series resistance was assessed repetitively in response to a $5 \mathrm{mV}$ pulse and compensated up to $70 \%$ throughout the recording. Cells exhibiting $>20 \%$ change in series resistance were excluded from analysis. mIPSCs were isolated in the presence of the ionotropic glutamatergic receptor antagonists ( $5 \mu \mathrm{M}$ NBQX, $40 \mu \mathrm{M}$ D-APV) and TTX $(1 \mu \mathrm{M})$ and recorded at a holding potential of $-70 \mathrm{mV}$. In some experiments, the identity of the mIPSCs was confirmed by exogenous application of gabazin $(5 \mu \mathrm{M})$ at the end of the recording session. The currents were recorded with Axoscope 8.1 software (Molecular Devices) and analysis of mIPSCs was performed blindly using the Mini Analysis Program 6.0 software (Synaptosoft). The absence of false-positive events was confirmed by visual inspection of each experiment. Cumulative distributions were generated using 100 consecutive mIPSCs, averaged across all cells. One hundred random points selected from each cell were concatenated to describe the cumulative distributions of events in each condition and then compared by Kolmogorov-Smirnov test. 
Statistical analysis. If not stated otherwise, all population data are expressed as mean \pm SEM. Paired Student's $t$ test was used to compare statistical significance between groups in ELISA experiments and unpaired Student's $t$ test was used to examine the statistical significance of the differences between groups in microscopy and qRT-PCR analysis; ANOVA was used for multiple comparisons. Cumulative distributions were compared using the Kolmogorov-Smirnov two-sample test. Significantly different values $\left({ }^{\star} p<0.05\right.$; ${ }^{* *} p<0.01$; $\left.{ }^{* *} p<0.001\right)$ are indicated in figures with asterisks.

Drugs. TTX was purchased from Abcam; ROCKi (Y-27632) was purchased from Millipore; tPA-Stop was purchased from American Diagnostica; k252a, TAT-pep5, and Stattic were purchased from Calbiochem; nifedipine, aprotinin, leupeptin, and AG490 were purchased from Sigma-Aldrich; CR-proBDNF recombinant (Escherichia coli) mutated human and mBDNF were purchased from Alomone Labs. NBQX, CNQX, and D-APV were obtained from the Molecular, Cellular, and Genomic Neuroscience Research Branch of the National Institute of Mental Health.

\section{Results}

Exogenous CR-proBDNF decreases cell-surface expression of GABA $_{\mathrm{A}} \mathrm{R}$ clusters

As a first attempt to determine whether proBDNF may affect the stability of $\mathrm{GABA}_{\mathrm{A}}$ Rs at the cell surface, we examined the effect of an acute application of exogenous CR-proBDNF. At 14 DIV, hippocampal cultures were preincubated with TTX $(1 \mathrm{~h}, 0.5 \mu \mathrm{M})$, NBQX $(10 \mathrm{~min}, 5 \mu \mathrm{M})$ and D-APV (10 $\mathrm{min}, 40 \mu \mathrm{M})$ to reduce regulated secretion of endogenous BDNF triggered by spontaneous activity. This treatment was followed by the addition of CRproBDNF $(25 \mathrm{ng} / \mathrm{ml}$ ) for $30 \mathrm{~min}$. Immunohistochemistry using the $\mathrm{GABA}_{\mathrm{A}} \mathrm{R} \beta_{2 / 3}$-specific antibody, in combination with antiMAP2 antibody, allowed a semiquantitative analysis of $\mathrm{GABA}_{\mathrm{A}} \mathrm{R}$ $\beta_{2 / 3}$ levels at the surface of pyramidal-like neurons in which the ratio $\mathrm{GABA}_{\mathrm{A}} \mathrm{R} \beta_{2 / 3} / \mathrm{MAP} 2$ and the average $\mathrm{GABA}_{\mathrm{A}} \mathrm{R} \beta_{2 / 3}$ perimeter were quantified in the somatic and proximal dendritic regions. The application of CR-proBDNF resulted in a significant decrease of $\mathrm{GABA}_{\mathrm{A}} \mathrm{R} \beta_{2 / 3}$ surface levels (47.40 $\pm 3.7 \%$ surface ratio; $p=0.0003$ compared with control, 35 neurons analyzed, $n=4$; Fig. $1 A, B)$. This effect was abolished in the presence of TAT-pep5 $(2 \mu \mathrm{M})$, a cell-permeable inhibitor of $\mathrm{p} 75^{\mathrm{NTR}}$ signaling $(109.02 \pm 3.5 \%$ surface ratio compared with control; $p=0.167$, 35 neurons analyzed, $n=4$; Fig. $1 A, B)$. The average perimeter of $\mathrm{GABA}_{\mathrm{A}} \mathrm{R} \beta_{2 / 3}$ clusters was also decreased in response to CRproBDNF $\left(0.29 \pm 0.02 \mu \mathrm{m}^{2}\right.$ in control vs $0.18 \pm 0.01 \mu \mathrm{m}^{2}$ in CR-proBDNF; $p=0.0005$ compared with control, 35 neurons analyzed, $n=4$; Fig. $1 C$ ), an effect prevented by TAT-pep5 $\left(0.27 \pm 0.03 \mu \mathrm{m}^{2} ; p=0.298\right.$ compared with control, 35 neurons analyzed, $n=4$; Fig. $1 C$ ).

Reductions in the perimeter of $\mathrm{GABA}_{\mathrm{A}} \mathrm{R} \beta_{2 / 3}$ clustering at the cell surface observed with CR-proBDNF treatment may be due to an increased lateral mobility from synaptic sites to extrasynaptic sites (Thomas et al., 2005; Goffin et al., 2010; Luscher et al., 2011), without decrease in the total membrane levels. It also may reflect an internalization of the cell-surface receptors to the cytoplasm, and/or a decrease in addressing receptors into the cell membrane. To confirm decrease in membrane expression, we performed a quantitative measurement of these changes using cell-surface ELISA experiments with the same $\mathrm{GABA}_{\mathrm{A}} \mathrm{R} \beta_{2 / 3}$-specific antibody (Jovanovic et al., 2004; Porcher et al., 2011). Addition of CR-proBDNF ( $25 \mathrm{ng} / \mathrm{ml}, 30 \mathrm{~min}$ ) led to a decrease in cell-surface expression of the $\beta_{2 / 3}$ subunit $(78.37 \pm 4.9 \%$ of control nonstimulated cultures, $p=0.0008, n=4$; Fig. $1 D)$. This effect was dependent on the activation of $\mathrm{p} 75^{\mathrm{NTR}}$ by the CR-proBDNF as it was abolished in the presence of TAT-pep5 $(2 \mu \mathrm{M}, 104.23 \pm 3.8 \%$ compared with control, $p=0.314, n=4$; Fig. $1 D)$. No significant difference was observed in the total levels of $\mathrm{GABA}_{\mathrm{A}} \mathrm{R} \beta_{2 / 3}$ subunit between control and treated cultures (Fig. 1E).

We also investigated, by qRT-PCR analysis, whether the application of CR-proBDNF could affect the level of mRNA transcripts encoding for $\mathrm{GABA}_{\mathrm{A}} \mathrm{R}$ subtypes containing $\beta_{3}$ subunits. No significant differences were found between $\mathrm{GABA}_{\mathrm{A}} \mathrm{R} \beta_{3}$ mRNA levels in control and proBDNF-treated cultures (Fig. $1 F$ ).

Thus, a continuous 30 min activation of $\mathrm{p} 75^{\mathrm{NTR}}$ by exogenous application of CR-proBDNF leads to a significant decrease in cell-surface expression and perimeter of $\mathrm{GABA}_{\mathrm{A}} \mathrm{R} \beta_{2 / 3}$ and does not change the level of $\mathrm{GABA}_{\mathrm{A}} \mathrm{R}$ transcripts and proteins.

\section{Endogenous accumulation of proBDNF decreases the density of GABAergic synapses and the size of $G_{A B A} R \beta_{2 / 3}$ clusters} To examine whether endogenous proBDNF modulates GABAergic synaptic connectivity, we investigated the effects of aprotinin ( $3 \mu \mathrm{g} / \mathrm{ml}, 12 \mathrm{~h}$ ), a serine protease inhibitor that blocks plasmin activity and prevents the extracellular cleavage of proBDNF into mBDNF (Lee et al., 2001). To confirm that aprotinin prevents conversion of proBDNF into mBDNF, we measured the concentration of proBDNF in hippocampal neuronal culture supernatants in control and aprotinin conditions using an ELISA proBDNF immune-detection assay. As illustrated in Figure $2 \mathrm{~A}$, endogenous proBDNF levels upon treatment with aprotinin (3 $\mu \mathrm{g} / \mathrm{ml}, 12 \mathrm{~h})$ increased significantly $(57.45 \pm 0.39 \mathrm{pg} / \mathrm{ml})$ compared with control $(4.0 \pm 1.15 \mathrm{pg} / \mathrm{ml} ; p<0.0001, n=3)$.

To identify functional GABAergic synapses, we performed double immunostaining against synaptobrevin (VAMP1), a marker of functional presynaptic membranes (Weber et al., 1998 ) and postsynaptic cell-surface expression of $\mathrm{GABA}_{\mathrm{A}} \mathrm{R} \beta_{2 / 3}$ clusters (Chih et al., 2005; Yu et al., 2007; Goffin et al., 2010). We counted the density of presynaptic and postsynaptic marker apposition at the somatodentritic level of MAP2-positive neurons. The level of colocalized clusters between VAMP1 and $\mathrm{GABA}_{\mathrm{A}} \mathrm{R}$ $\beta_{2 / 3}$ of MAP2-positive cells was estimated in control condition (33.8 \pm 3.4\%, 35 neurons analyzed, $n=4$; Fig. 2 B, C). After $12 \mathrm{~h}$ treatment with aprotinin, we observed a significant decrease in the colocalization between $\mathrm{GABA}_{\mathrm{A}} \mathrm{R} \beta_{2 / 3}$ clusters expressed at the cell-surface and VAMP1-positive presynaptic terminals (25.2 \pm $1.6 \%, p=0.0007$ compared with control, 35 neurons analyzed, $n=4$; Fig. $2 B, C$ ). This decrease in colocalized puncta between postsynaptic $\mathrm{GABA}_{\mathrm{A}} \mathrm{R} \beta_{2 / 3}$ and presynaptic VAMP1 staining was prevented by treatment of cell cultures with TAT-pep5 before application of aprotinin $(30.8 \pm 2.1 \%, p=0.216$ compared with control, 35 neurons analyzed, $n=4$; Fig. $2 B, C$ ).

The observed reduction in the density of GABAergic synapses may reflect a decrease in postsynaptic cell-surface expression of $\mathrm{GABA}_{\mathrm{A}} \mathrm{R}$ clusters, as observed previously during acute application of CR-proBDNF, and/or a reduction in the number of presynaptic terminals. To evaluate these possibilities, we performed detailed quantitative analysis of the area fraction of VAMP1 and $\mathrm{GABA}_{\mathrm{A}} \mathrm{R} \beta_{2 / 3}$ puncta of MAP2-positive neurons, following treatment with aprotinin. Our analysis revealed a significant decrease in the area fraction and average perimeter of surface $G_{A B A} R$ $\beta_{2 / 3}$-positive puncta following activation of the $\mathrm{proBDNF} / \mathrm{p} 75^{\mathrm{NTR}}$ pathway. After treatment with aprotinin, the area fraction and perimeter were respectively $49.9 \pm 6.4 \%$ and $51.4 \pm 8.6 \%$ of control ( $p=0.0009,35$ neurons analyzed, $n=4$; Fig. $2 B, D, E)$. Both effects were prevented by TAT-pep5 ( $p=0.345$ compared with control, 35 neurons analyzed, $n=4$; Fig. $2 B, D, E)$.

To assess changes in presynaptic terminals, we analyzed the area fraction of VAMP1-positive puncta of MAP2-positive neu- 
A

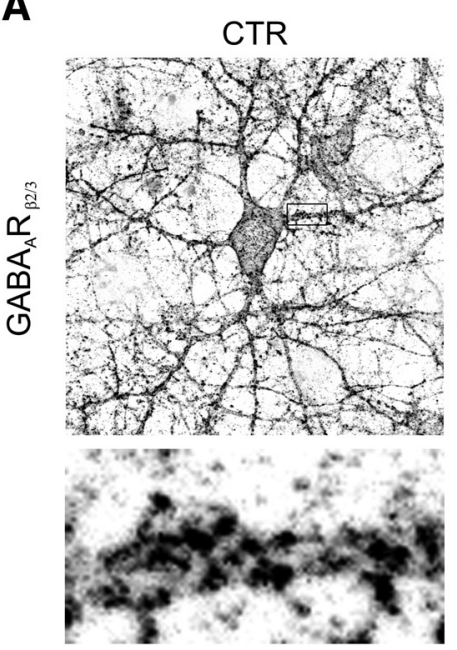

B

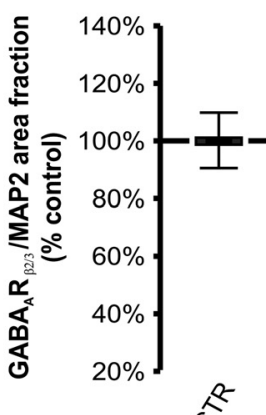

D

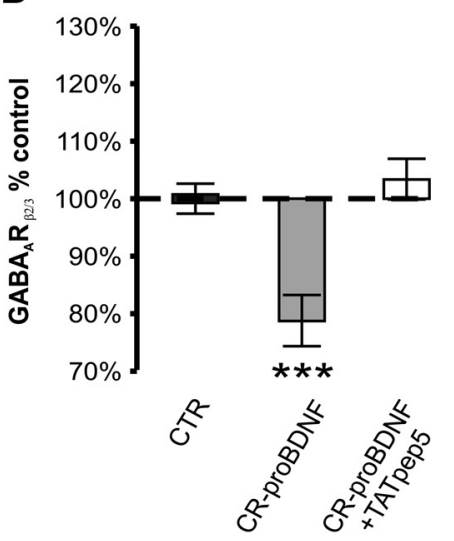

CR-proBDNF

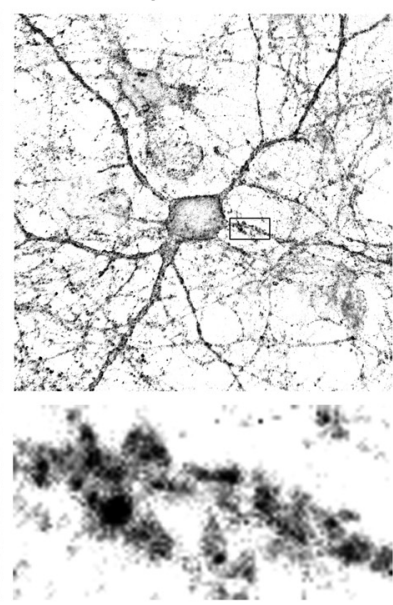

CR-proBDNF

+ TATpep5

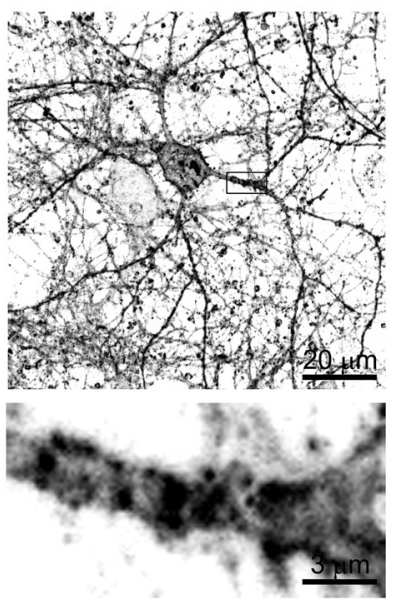

C

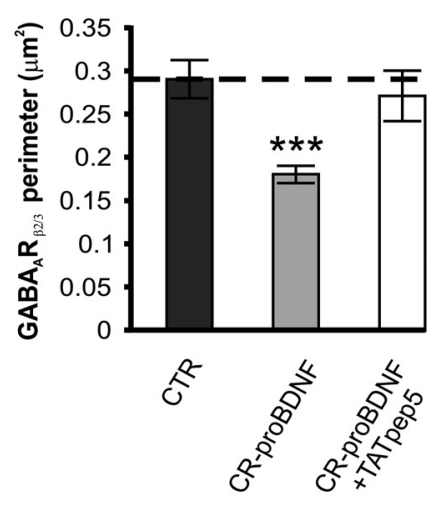

Total

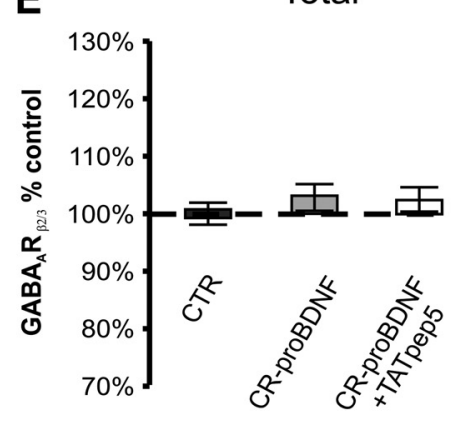

$\mathbf{F}$

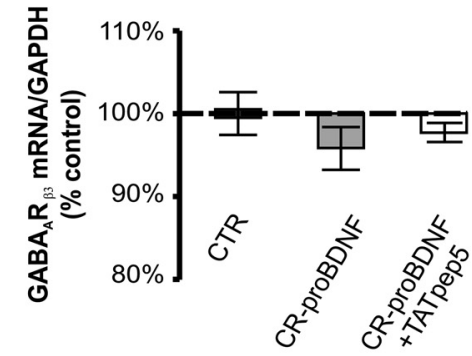

Figure 1. Exogenous application of CR-proBDNF downregulates $G A B A_{A} R$ cell-surface expression. $A$, Cultured neurons ( 14 DIV), in control conditions (CTR), or treated with CR-proBDNF (CRproBDNF) or CR-proBDNF plus TAT-pep5 (CR-proBDNF + TATpep5) and immunolabeled with $\mathrm{GABA}_{\mathrm{A}} \mathrm{R} \beta_{2 / 3}$ subunit-specific mouse monoclonal antibody to reveal expression at the cell surface, and following permeabilization, immunolabeled with anti-MAP2 chicken polyclonal antibody (data not shown) to reveal neuronal cells. Scale bars: top, $20 \mu \mathrm{m} ;$ bottom, $3 \mu \mathrm{m}$. B, C, Quantification of surface $G A B A_{A} R \beta_{2 / 3}$ intracellular MAP2 fluorescence ratio $(\boldsymbol{B})$ and the average perimeter of $G A B A_{A} R \beta_{2 / 3}$ clusters $(\boldsymbol{C})$ at the cell surface in the proximal dendrites and soma of MAP2-positive neurons, treated with CR-proBDNF alone ( $25 \mathrm{ng}, 30 \mathrm{~min}$ ), or CR-proBDNF plus TAT-pep5 (CR-proBDNF + TATpep5; $2 \mu \mathrm{M}$ ), in comparison with the vehicle-treated control (CTR). Thirty-five neurons

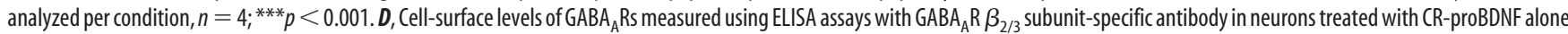
( $25 \mathrm{ng}, 30 \mathrm{~min}$ ), or in the presence of TAT-pep5 (CR-proBDNF + TATpep5; $2 \mu \mathrm{m}$ ), and expressed as a percentage of vehicle-treated controls (CTR). $E$, Total GABA $A_{A} R \beta_{2 / 3}$ subunit expression normalized to control nontreated conditions. The total level of $\beta_{2 / 3}$ subunit levels remains unchanged. $n=4$; ${ }^{* * *} p<0.001$. $\boldsymbol{F}$, Relative expression of GABA $\mathrm{R} \beta_{3}$ gene in neurons treated with CR-proBDNF alone ( $25 \mathrm{ng}, 30 \mathrm{~min}$ ), or in the presence of TAT-pep5 (CR-proBDNF + TATpep5; $2 \mu \mathrm{M}$ ), and expressed as a percentage of vehicle-treated controls (CTR). GABA $A_{A} R \beta_{3}$ gene expression was normalized to the expression of the housekeeping gene, GAPDH, in the same RNA preparation. $n=6 ; p>0.05$. 
A

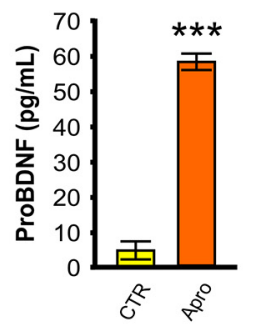

C

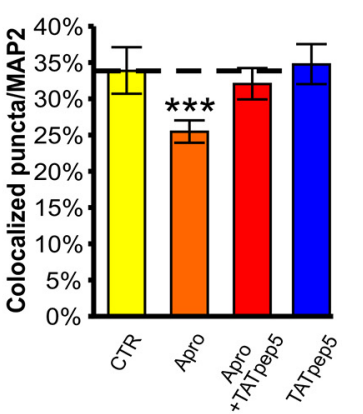

D

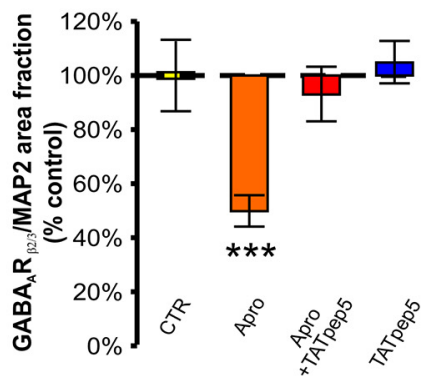

G

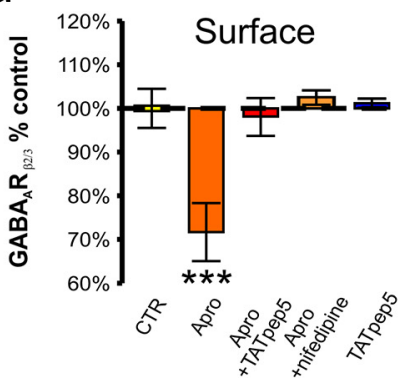

B
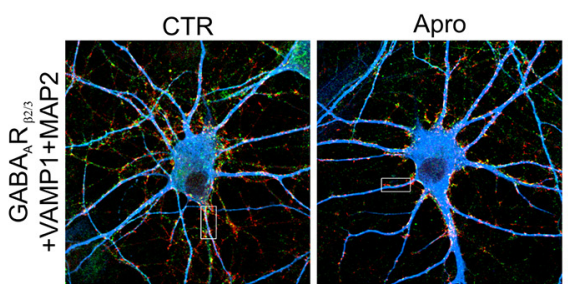

Apro
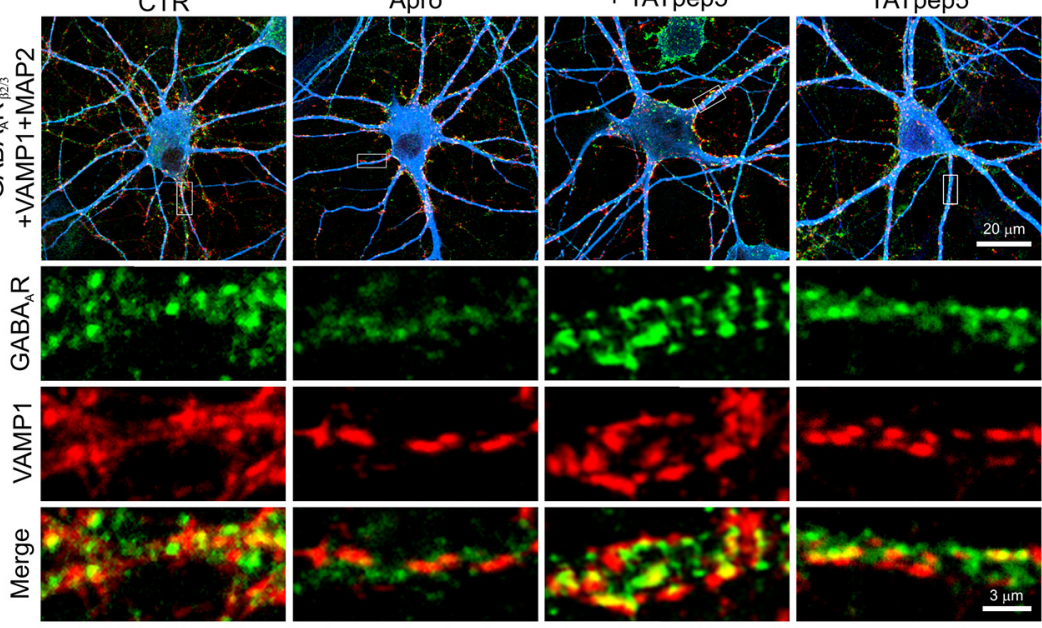

E

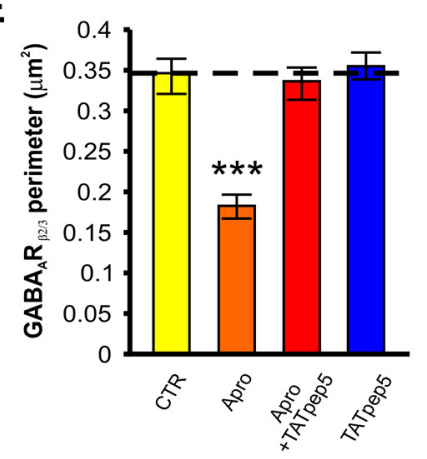

H

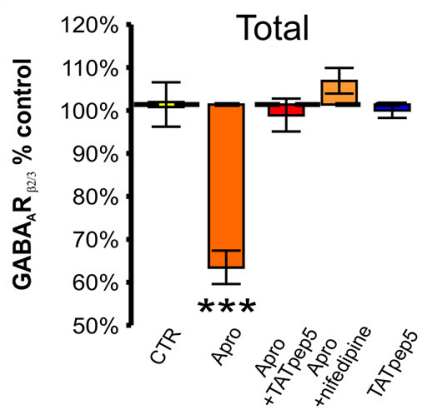

F

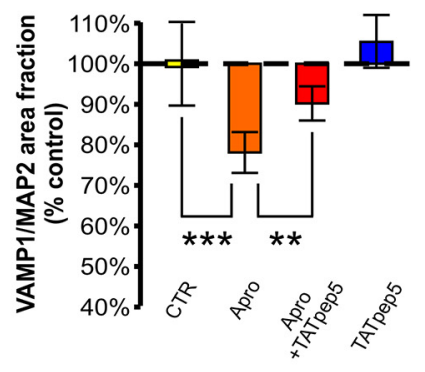

I

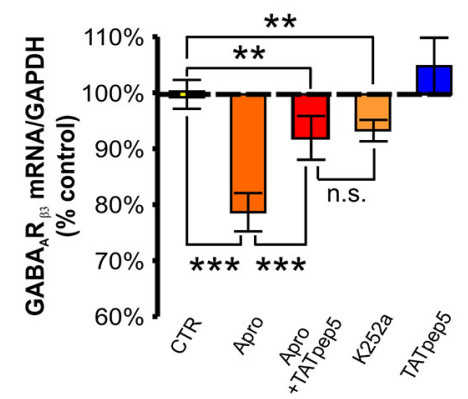

Figure 2. Endogenous proBDNF decreases the colocalization of postsynaptic GABA $\mathrm{R} \beta_{2 / 3}$ clusters with presynaptic VAMP1 puncta. $A$, proBDNF protein levels in hippocampal culture supernatants in control and aprotinin conditions. Treatment with aprotinin (Apro; $3 \mu \mathrm{g} / \mathrm{ml}, 12 \mathrm{~h}$ ) increases significantly the concentration of proBDNF in the supernatant compared with control (CTR). $n=3 ;{ }^{* * *} p<0.001$. B, Hippocampal cultures (14 DIV) were treated for $12 \mathrm{~h}$ with vehicle (CTR), aprotinin (Apro), aprotinin plus TAT-pep5 (Apro + TATpep5), or TAT-pep5 alone, and stained for $\mathrm{GABA}_{\mathrm{A}} \mathrm{R} \beta_{2 / 3}$ subunit (green), VAMP1 (red), and MAP2 (blue). Scale bars: top, $20 \mu \mathrm{m}$; bottom, $3 \mu \mathrm{m}$. $\boldsymbol{C}$, The percentage of $\beta_{2 / 3}$ subunit-positive clusters that colocalized with VAMP1 puncta/intracellular MAP2 fluorescence ratio was significantly reduced in cultures treated with aprotinin (3 $\mu \mathrm{g} / \mathrm{ml}, 12 \mathrm{~h}$ ). $\boldsymbol{D}, \boldsymbol{E}, \mathrm{Aprotinin}(\mathrm{Apro})$ significantly decreased the average $\beta_{2 / 3}$ subunit-positive area fraction/intracellular MAP2 fluorescence ratio $(\boldsymbol{D})$ and the average perimeter of $\mathrm{GABA}_{\mathrm{A}} \mathrm{R} \boldsymbol{\beta}_{2 / 3}$ clusters $(\boldsymbol{E})$ at the cell surface of MAP2-positive neurons, in comparison with the vehicle-treated control (CTR), in the presence of TAT-pep5 (Apro + TATpep5) or TAT-pep5 alone (TATpep5). Thirty-five neurons analyzed per condition, $n=4 ;{ }^{* * *} p<0.001$. F, Quantification of surface VAMP1/MAP2 fluorescence ratio, in neurons treated with aprotinin alone (Apro), aprotinin plus TAT-pep5 (Apro + TATpep5), or TAT-pep5 alone (Tatpep5; $2 \mu \mathrm{m}$ ), in comparison with the vehicle-treated control (CTR). Thirty-five neurons analyzed per condition, per experiment; $n=4$; ${ }^{* * *} p<0.001$, ${ }^{* *} p<0.01$. G, Cell-surface levels of $\mathrm{GABA}_{\mathrm{A}} \mathrm{Rs}$ measured using ELISA assays with GABA $\mathrm{R} \beta_{2 / 3}$ subunit-specific antibody in neurons treated with aprotinin alone (Apro; $3 \mu \mathrm{g} / \mathrm{ml}$, $12 \mathrm{~h}$ ), with Apro in the presence of TAT-pep5 (Apro + TAT-pep5; $2 \mu \mathrm{m}$ ), with Apro and nifedipine (Apro + nifedipine; $10 \mu \mathrm{m}$ ), and only in the presence TAT-pep5 (TAT-pep5; $10 \mu \mathrm{M}$ ), and expressed as a percentage of vehicle-treated controls (CTR). $\boldsymbol{H}$, Total $\mathrm{GABA}_{A} \mathrm{R} \beta_{2 / 3}$ subunit expression normalized to control nontreated conditions. $n=6$; ${ }^{* * *} p<0.001$. $\boldsymbol{I}$, Relative expression of $\mathrm{GABA}_{\mathrm{A}} \mathrm{R} \beta_{3}$ mRNA transcripts in neurons treated with aprotinin (Apro; $3 \mu \mathrm{g} / \mathrm{ml}, 12 \mathrm{~h}$ ), with aprotinin and TAT-pep5 (Apro + TATpep5; $2 \mu \mathrm{m}$ ), with K252a alone (200 nm), or with TAT-pep5 alone $(2 \mu \mathrm{m})$, and expressed as a percentage of vehicle-treated controls (CTR). GABA $A_{A} R \beta_{3}$ subunit gene expression was normalized to the expression of the housekeeping gene, GAPDH, in the same RNA preparation. $n=6 ;{ }^{* *} p<0.001$. 
rons. After a $12 \mathrm{~h}$ treatment with aprotinin, a significant reduction in the average area fraction of VAMP1 puncta was observed (78.5 $\pm 4.7 \%$ compared with control, $p=0.0006,35$ neurons analyzed, $n=4$ experiments; Fig. $2 B, F)$. This change of VAMP1positive puncta under treatment with aprotinin was sensitive to TAT-pep5 (90.4 $\pm 3.8 \%$ compared with control, $p=0.067,35$ neurons analyzed, $n=4$; Fig. $2 B, F)$.

We next used ELISA experiments to evaluate the cell-surface and cytoplasmic expression of $\mathrm{GABA}_{\mathrm{A}} \mathrm{R} \beta_{2 / 3}$ subunits after treatments with aprotinin. We observed that aprotinin reduces the expression of $\mathrm{GABA}_{\mathrm{A}} \mathrm{Rs}$ at the membrane $(71.8 \pm 3.6 \%$ compared with control; $p=0.0008, n=9$; Fig. $2 G$ ) and cytoplasmic $(59.0 \pm 4.1 \%$ compared with control; $p=0.0005, n=9$; Fig. $2 H)$ levels. These effects were prevented by TAT-pep5 (98.4 $\pm 3.5 \%$ and $97.5 \pm 8.3$ respectively, compared with control, $p=0.274$, $n=6$; Fig. $2 G, H)$.

To investigate whether the endogenous release of proBDNF depends on the regulated secretory pathway (Haubensak et al., 1998; Zhou et al., 2004; Yang et al., 2009), we analyzed the effect of aprotinin in the presence of nifedipine $(10 \mu \mathrm{M})$, an inhibitor of L-type VGCCs, which are known to prevent dendritic release of BDNF (Kuczewski et al., 2008a). In the presence of nifedipine, aprotinin failed to decrease the expression of $\mathrm{GABA}_{\mathrm{A}} \mathrm{R} \beta_{2 / 3}$ subunits at the membrane $(103.1 \pm 2.2 \%$ compared with control, $p=0.363, n=6$; Fig. $2 G)$ and cytoplasmic (108.2 $\pm 3.1 \%$ compared with control, $p=0.416, n=6$; Fig. $2 H$ ) levels.

To further determine whether the diminution of $G_{A B A} R$ $\beta_{2 / 3}$ subunits induced by aprotinin reflects modulation of gene transcription, we performed qRT-PCR analysis of GABA $\mathrm{R} \beta_{3}$ subunit mRNA levels following treatment with aprotinin. We found significant differences in $\mathrm{GABA}_{\mathrm{A}} \mathrm{R} \beta_{3}$ subunit mRNA levels between control and aprotinin-treated cultures $(78.8 \pm 3.1 \%$ compared with control; $p=0.0003, n=6$; Fig. $2 I$ ). This change in $\mathrm{GABA}_{\mathrm{A}} \mathrm{R} \beta_{3}$ subunit levels was significantly attenuated by TAT-pep5 compared with aprotinin alone ( $p=0.0007$; Fig. $2 I)$.

The levels remained, however, reduced compared with control $(91.3 \pm 3.3 \%$ compared with control; $p=0.008, n=6$; Figure $2 I$ ), this difference might be due to the lack of TrkB activation by $\mathrm{mBDNF}$ during treatment with aprotinin. To test this hypothesis, we next treated the cultures with K252a (200 nM), a membrane-permeable inhibitor of protein tyrosine kinase coupled to the Trk receptor family. In the presence of K252a, the level of $\mathrm{GABA}_{\mathrm{A}} \mathrm{R} \beta_{3}$ mRNAs was similar to treatment with aprotinin in the presence of TAT-pep5 (92.8 $\pm 2.2 \%$ compared with control; $p=0.004, n=6$; Fig. $2 I)$.

In all experiments, treatment of neuronal cultures with TATpep5 alone did not produce any detectable effect on $\mathrm{GABA}_{\mathrm{A}} \mathrm{R}$ protein and mRNA levels (Fig. $2 B-I$ ).

Together, these data indicate that endogenous activation of p $75^{\text {NTR }}$ significantly reduces both the density of functional GABAergic synapses and the synthesis of $\mathrm{GABA}_{\mathrm{A}} \mathrm{R} \beta_{3}$ mRNA transcripts.

\section{CR-proBDNF-Cherry altered miniature GABAergic synaptic activity}

To further show that the effects of chronic treatment with aprotinin are linked to activity-dependent secretion of proBDNF, we transfected neurons with a CR-proBDNF tagged with Cherry (CR-proBDNF Cherry). In this model, Cherry-tagged proBDNF can be targeted into dendritic secretory granules of the regulated pathway of secretion, and released from the postsynaptic target cells during spontaneous network activity (Haubensak et al., 1998; Kuczewski et al., 2008a).
We first confirmed that expression of CR-proBDNF in transfected cells leads to a similar decrease in $\mathrm{GABA}_{\mathrm{A}} \mathrm{R}$ surface expression similar to those observed in CR-proBDNF and aprotinin-treated cultures. To this end, we labeled surface $G_{A B A}$ Rs using the $\mathrm{GABA}_{\mathrm{A}} \mathrm{R} \beta_{2 / 3}$ subunit antibody. Neurons were costained with MAP2. As illustrated (Fig. $3 A, B$ ), $\mathrm{GABA}_{\mathrm{A}} \mathrm{R} \beta_{2 / 3}$ surfaces were significantly reduced in transfected neurons with CR-proBDNFCherry compared with control Cherry neurons (control Cherry: $44.5 \pm 5.6 \%$ and $25.2 \pm 7.1 \%$ in CR-proBDNF-Cherry transfected cells, $p=0.0008,15$ neurons analyzed per condition, normalized to MAP2, $n=3$ ).

We then performed whole-cell patch-clamp recordings of $\mathrm{GABA}_{\mathrm{A}} \mathrm{R}$ mIPSCs in pyramidal-like cells transfected at $10 \mathrm{DIV}$ after plating. At 14 DIV, mIPSCs were observed in $>80 \%$ of both CR-proBDNF and control neurons. At this age, neurons overexpressing CR-proBDNF (CR-proBDNF Cherry) exhibited a striking difference in mIPSC interevent intervals $(1.2 \pm 0.04 \mathrm{~s}$ in CR-proBDNF, 14 neurons analyzed, $n=4$ ) and amplitude (57 \pm $1.1 \mathrm{pA}$ in CR-proBDNF, 14 neurons analyzed, $n=4)$ compared with Cherry-expressing neurons $(0.5 \pm 0.02 \mathrm{~s}, p<0.001$, and $74.3 \pm 1.4 \mathrm{pA}, p<0.001,14$ neurons analyzed, $n=4$; Fig. $3 C-F)$. The kinetic properties of $\mathrm{mGABA}_{\mathrm{A}}$ PSCs were unchanged (Fig. $3 G, H)$. The membrane capacitance of the recorded cells, an indicator of neuronal size (Colin-Le Brun et al., 2004), was not different between CR proBDNF-Cherry-expressing and Cherryexpressing neurons (Fig. 3I). Therefore, these results show that proBDNF downregulates $\mathrm{GABA}_{\mathrm{A}} \mathrm{R}$ function at the synapse.

Together, these results indicate that proBDNF leads to a decrease of $\mathrm{GABA}_{\mathrm{A}} \mathrm{R}$ surface density, which is associated with the reduction of $\mathrm{GABA}_{\mathrm{A}} \mathrm{R}$ mIPSC frequency and amplitude.

\section{Apoptosis is not triggered by proBDNF}

To explore the possibility that the decrease of GABAergic synapses mediated by proBDNF/p7 $5^{\mathrm{NTR}}$ signaling might be due to cellular loss, we performed double immunostaining for cleaved caspase-3, a marker for cell apoptosis (Logue and Martin, 2008) and MAP2, and quantified the ratio of cleaved caspase-3-positive neurons to total MAP2-positive neuronal number. A comparison of the number of cleaved caspase-3-positive neurons to the total of MAP2-positive neuronal number showed that the number of apoptotic neurons did not increase with overexpression of CRproBDNF Cherry or with exogenous application of CRproBDNF (Fig. $4 B$ ), or with treatment with aprotinin (Fig. $4 B$; $p>0.05$ compared with control, 15 neurons analyzed per condition, $n=3$; Fig. $4 C$ ).

Thus, the previously observed diminutions of $\mathrm{GABA}_{\mathrm{A}}$ Rs at the morphological and functional levels are not due to an apoptotic mechanism triggered by proBDNF.

\section{ProBDNF activates the RhoA-ROCK-PTEN pathway and promotes $\mathrm{GABA}_{\mathrm{A}} \mathrm{R}$ dephosphorylation and endocytosis} Cell-surface stability of $\mathrm{GABA}_{\mathrm{A}}$ Rs is regulated by phosphosensitive interactions of a $\beta$ subunit where dephosphorylation of $\beta_{3}$ Ser408/409 facilitates clathrin-mediated endocytosis of $\mathrm{GABA}_{\mathrm{A}}$ Rs (Jovanovic et al., 2004; Kittler et al., 2005). Because CR-proBDNF application leads to a decrease in cell-surface expression of $\mathrm{GABA}_{\mathrm{A}} \mathrm{Rs}$, we next sought to determine whether any changes in the levels of $\mathrm{GABA}_{\mathrm{A}} \mathrm{R}$ phosphorylation state occurred upon the activation of $\mathrm{p} 75^{\mathrm{NTR}}$ by exogenous application of CR-proBDNF.

By immunoblotting neuronal lysates with an anti-phospho- $\beta_{3}$ subunit antibody, we detected a significant CR-proBDNF/ p $75^{\mathrm{NTR}}$-dependent decrease in the phosphorylation state of 
A

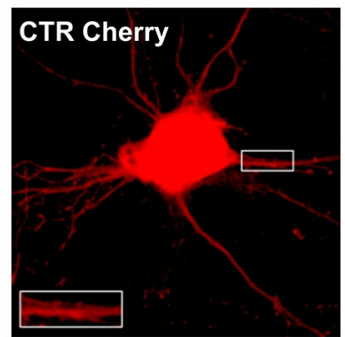

CR-proBDNF Cherry

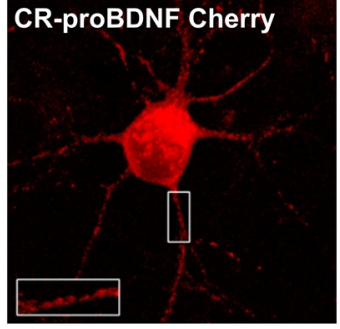

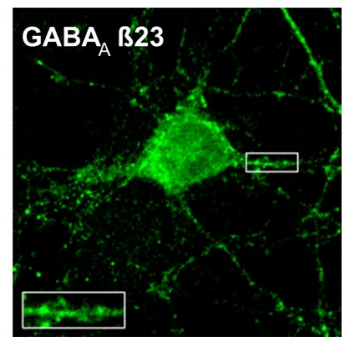

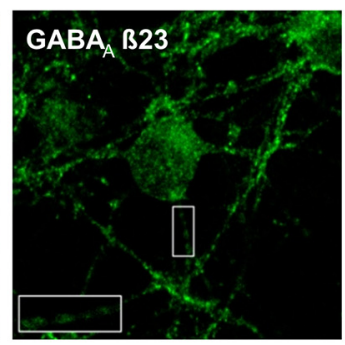

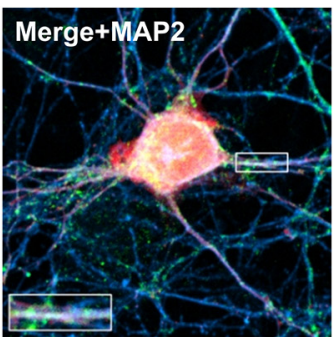

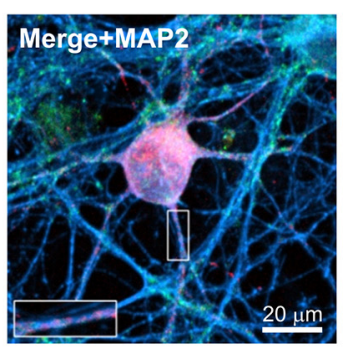

B

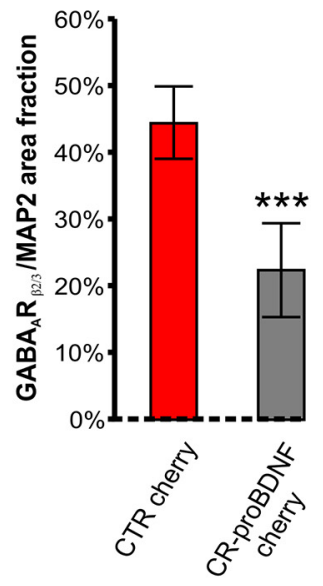

C

CTR Cherry

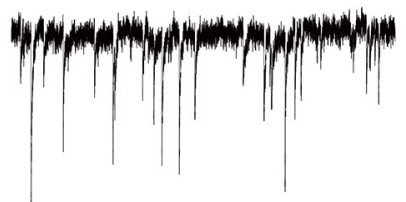

20pA

1s
CR-proBDNF Cherry

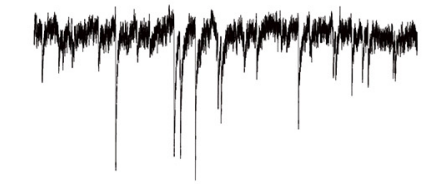

D

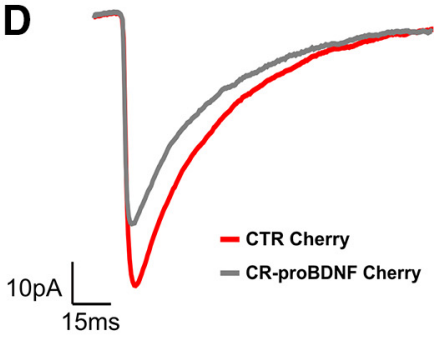

E

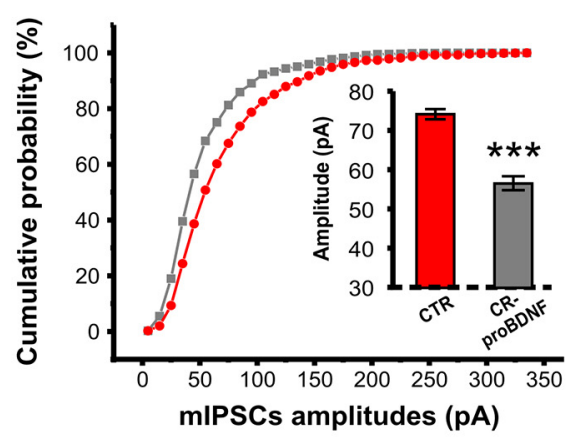

F

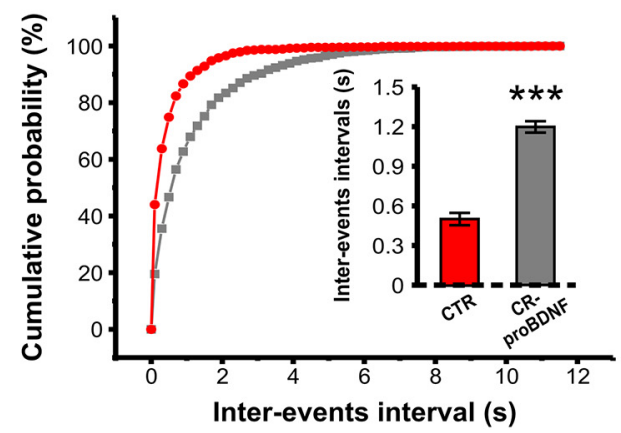

G

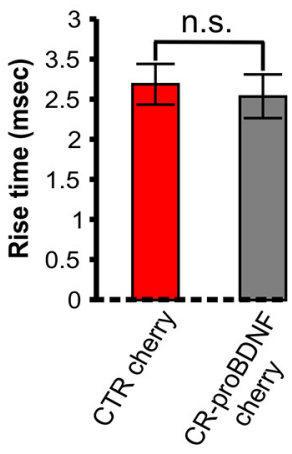

H

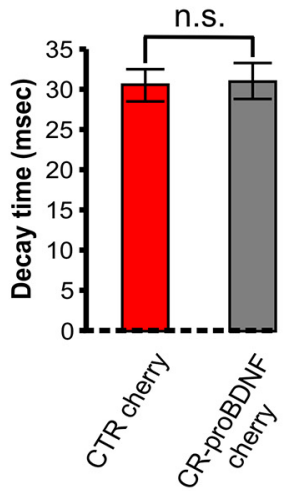

I

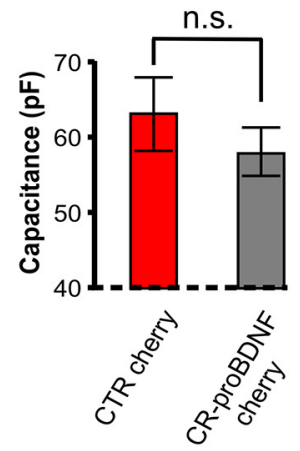

Figure 3. $G A B A_{A} R$ currents in neurons transfected with CR-ProBDNF and neurons transfected with Cherry. $A$, Transfected neurons with Cherry (CTR Cherry; top), or CR-proBDNF Cherry (bottom) and immunolabeled with $G A B A_{A} R \beta_{2 / 3}$ subunit-specific mouse monoclonal antibody to reveal expression at the cell surface, and following permeabilization, immunolabeled with anti-MAP2 rabbit polyclonal. Scale bar, $20 \mu \mathrm{m}$. B, Quantification of surface $\mathrm{GABA}_{\mathrm{A}} \mathrm{R} \beta_{2 / 3}$ /intracellular MAP2 fluorescence ratio. Fifteen neurons analyzed per condition, $n=3$; ${ }^{* * *} p<0.001$. C, Representative recordings of mIPSCs from neurons transfected with Cherry (left) and CR-ProBDNF Cherry (right). D. Illustration of average amplitude in neurons transfected with Cherry (red) and CR-ProBDNF Cherry (gray). $\boldsymbol{E}, \boldsymbol{F}$, Cumulative distributions of mIPSC amplitudes and interevent intervals. Insets in $\boldsymbol{E}$ and $\boldsymbol{F}$ display the mean \pm SEM amplitude and interevent intervals respectively (Kolmogorov-Smirnov test, ${ }^{* * *} p<0,001$ for amplitude and interevent interval). $\mathbf{G}, \boldsymbol{H}$, Rise time $(\boldsymbol{G})$ and decay time $(\boldsymbol{H})$. $\boldsymbol{I}$, Plot illustrates mean of neuron capacitance. $n=14$ neurons per condition. 
A

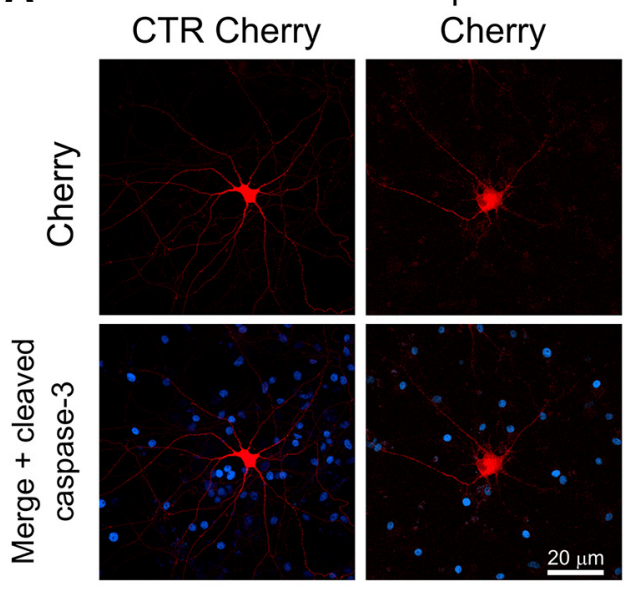

C

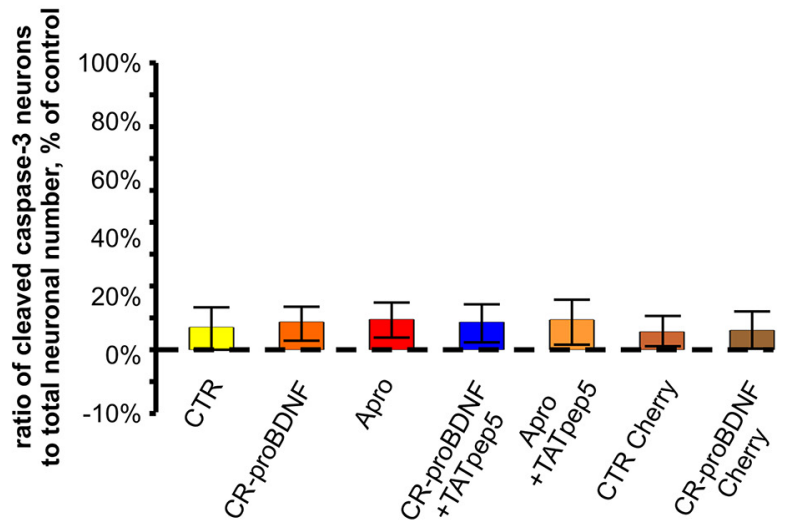

B
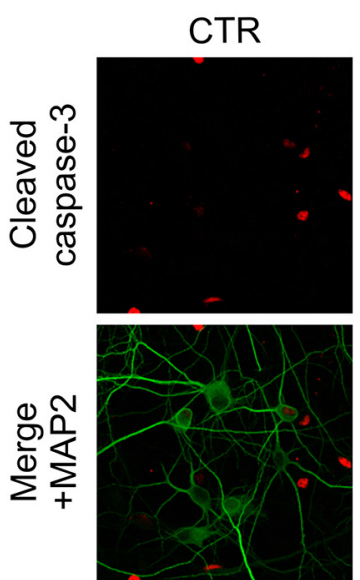
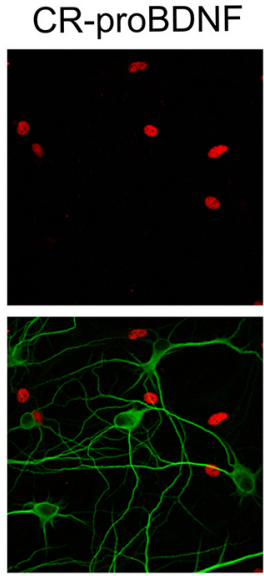

CR-proBDNF +TATpep5
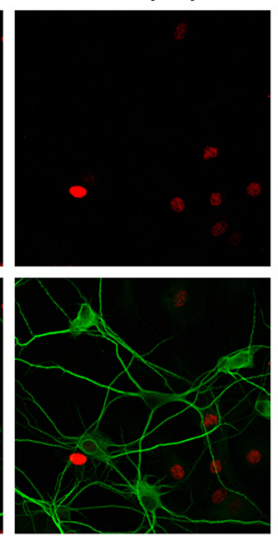
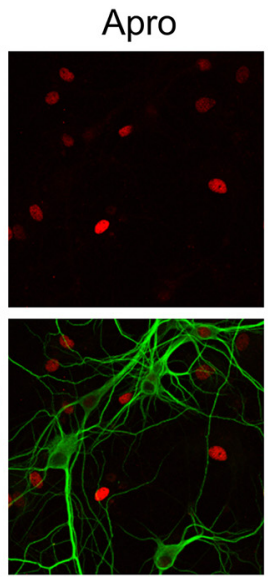

Apro +TATpep5
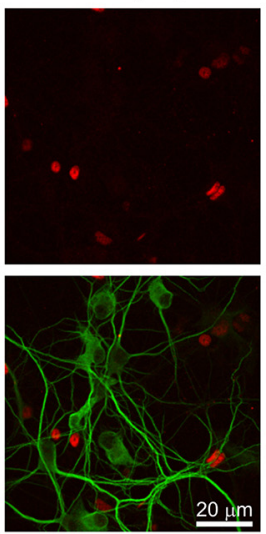

Figure 4. Apoptosis is not triggered by proBDNF. A, Image of hippocampal neurons transfected at 10 DIV with the CR-proBDNF Cherry (in red) and/or Cherry (in red), and costained at 14 DIV with the cleaved caspase-3 (in blue). B, Cultured hippocampal neurons (14 DIV) in control conditions (CTR), or treated with CR-proBDNF (25 ng, 30 min), or CR-proBDNF plus TAT-pep5 (CR-proBDNF + TATpep5; $2 \mu \mathrm{M}$ ), or aprotinin (Apro; $3 \mu \mathrm{g} / \mathrm{ml}, 12 \mathrm{~h}$ ), or aprotinin plus TAT-pep5 (Apro + TATpep5; $2 \mu \mathrm{M}$ ), and immunolabeled with cleaved caspase-3 antibody (red), and costained with anti-MAP2 antibody (green). C, Ratio of cleaved caspase-3-positive (apoptotic) neuronal number to total MAP2-positive cells, and expressed as a percentage of vehicle-treated controls (CTR). Overexpression of CR-proBDNF (CR-proBDNF Cherry), or exogenous application of CR-proBDNF (CR-proBDNF) or treatment with aprotinin (Apro) did not increase the number of apoptotic neurons compared with control (CTR). Fifty neurons analyzed per condition, per experiment; $n=4 ; p>0.05$.

$\mathrm{GABA}_{\mathrm{A}} \mathrm{R} \beta_{3}$ subunits $(63.36 \pm 5.6 \%$ of control nonstimulated cultures, $p=0.007, n=6$; Fig. $5 A)$. This effect was significantly attenuated by the $\mathrm{p} 75^{\mathrm{NTR}}$ signaling inhibitor TAT-pep5 (87.2 \pm $2.5 \%$ compared with control, $p=0.422, n=6$; Fig. $5 A$ ). We next investigated the contribution of RhoA and JAK 2 and their respective signaling pathways in the control of $\mathrm{GABA}_{\mathrm{A}} \mathrm{R}$ trafficking and synthesis that might be activated by proBDNF/p $75^{\mathrm{NTR}}$. We found that the decrease in the phosphorylation state of $\mathrm{GABA}_{\mathrm{A}} \mathrm{Rs}$ was prevented by the inhibitor of Rho kinase (ROCKi; $99.70 \pm$ $5.2 \%$ of control nonstimulated cultures, $p=0.470, n=5$; Fig. $5 A$ ), the downstream effector of the small GTPase RhoA (Yamashita and Tohyama, 2003). However, it was unaffected by the presence of Janus kinase 2 (JAK2) inhibitor AG490 (58.05 \pm $7.8 \%$ of control nonstimulated cultures, $p=0.005, n=4$; Fig. $5 A)$, and the STAT3 inhibitor Stattic $(69.63 \pm 8.1 \%$ of control nonstimulated cultures, $p=0.031, n=4$; Fig. $5 A$ ). In all experiments, the total level of $\mathrm{GABA}_{\mathrm{A}} \mathrm{R} \beta_{3}$ remained stable (Fig. $5 A$ ). ELISA immunoassays confirmed the role of the RhoA-ROCK pathway by a decrease in the cell-surface expression of $\mathrm{GABA}_{\mathrm{A}} \mathrm{R}$ $\beta_{2 / 3}$ subunits induced by the CR-proBDNF (Fig. 1). Thus, ROCKi abolished the decrease in cell-surface expression of
$\mathrm{GABA}_{\mathrm{A}}$ Rs induced with the CR-proBDNF (104.2 $\pm 5.7 \%$ compared with control, $p=0.483, n=3$; Fig. $5 B$ ). No significant difference was observed in the total levels of $\mathrm{GABA}_{\mathrm{A}} \mathrm{R} \beta_{2 / 3}$ subunit (Fig. 1; CR-proBDNF with ROCKi, $103.25 \pm 1.9 \%$; ROCKi alone, $102.2 \pm 5.8 \%$, compared with control).

To further decipher the molecular mechanism underlying the proBDNF-p75 ${ }^{\text {NTR }}$-RhoA-ROCK-mediated downregulation of GABAARs, we analyzed the expression of PTEN. PTEN, which negatively regulates membrane expression of GABAARs (Liu et al., 2010), is a dual protein/lipid phosphatase expressed downstream of the $\mathrm{p} 75^{\mathrm{NTR}}$-RhoA-ROCK pathway (Li et al., 2005; Song et al., 2010). Western blotting analysis performed on hippocampal neurons treated with CR-proBDNF showed an increase in PTEN levels (Fig. 5C). The level of pPTEN did not change significantly. Thus the increase of total PTEN relative to pPTEN indicates an increase in the dephosphorylated form of PTEN (72.5 \pm $5.3 \%$ compared with control, $p=0.021, n=5$; Fig. $5 C$ ), which is the active form of the phosphatase (Vazquez et al., 2000; Maccario et al., 2007). To confirm the role of the RhoA-ROCK pathway in proBDNF-induced PTEN activity, we treated cultured hippocampal neurons with ROCKi. In the presence of ROCKi, CR- 


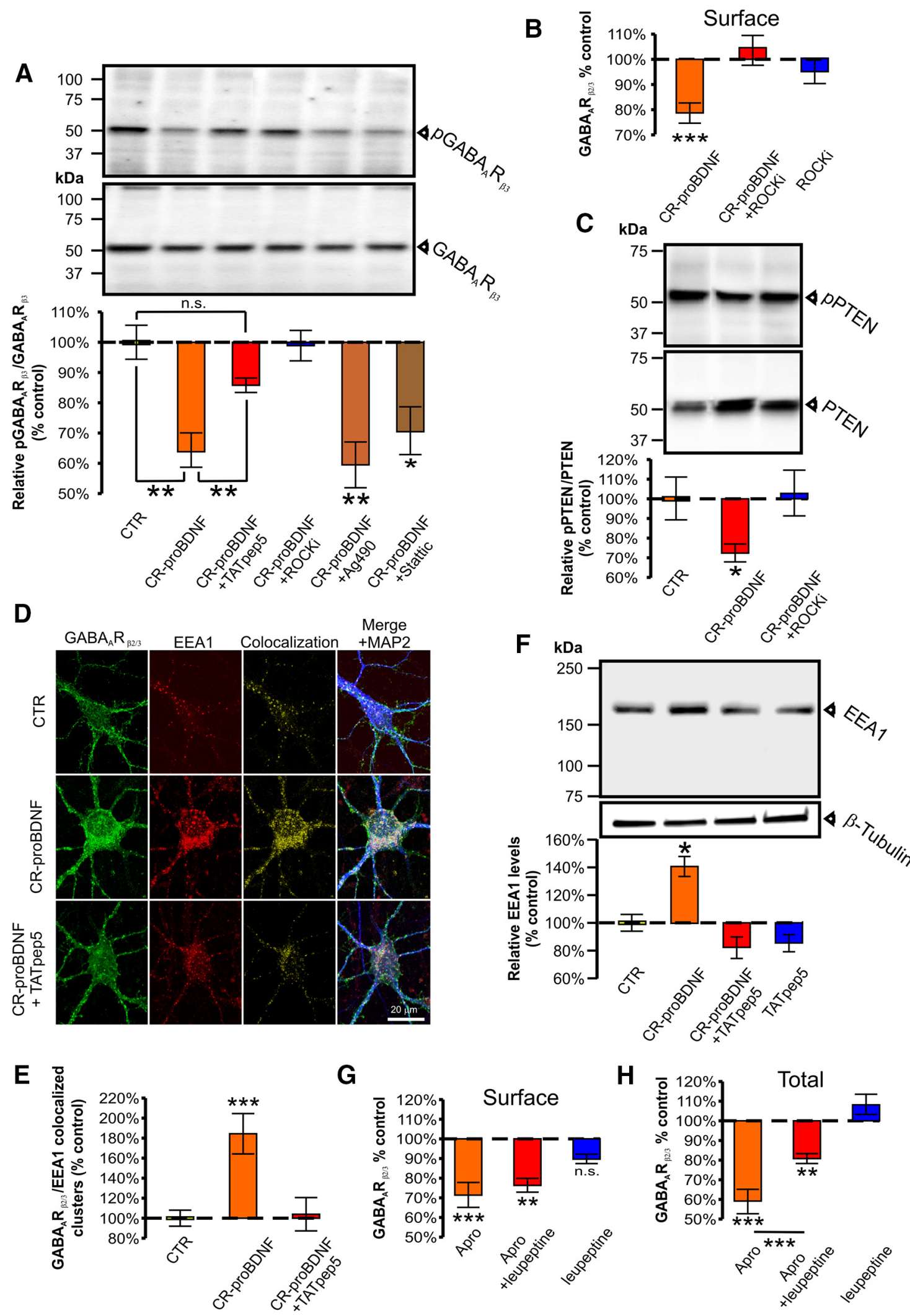

Figure 5. ProBDNF activates the RhoA-ROCK-PTEN pathway and promotes $G A B A_{A} R$ dephosphorylation and endocytosis. $A$, CR-proBDNF decreases the phosphorylation of Ser408/409 in the $G A B A_{A} R \beta_{3}$ subunit $\left(p G A B A_{A} R \beta_{3}\right.$ ). Total cellular proteins were analyzed using Western blot with polyclonal GABA $R A_{A} \beta_{3}$ subunit and $p G A B A_{A} R \beta_{3}$ subunit antibodies. Hippocampal neurons were treated with vehicle (CTR), CR-proBDNF (25 ng, $30 \mathrm{~min}$ ), CR-proBDNF plus TAT-pep5 (CR-proBDNF + TATpep5; $2 \mu \mathrm{m}$ ), CR-proBDNF plus ROCKi (CR-proBDNF + ROCKi; $50 \mu \mathrm{m})$, CR-proBDNF plus Ag490 (CR-proBDNF + Ag490; $50 \mu \mathrm{m}$ ), or CR-proBDNF plus Stattic (CR-proBDNF + Stattic; $10 \mu \mathrm{M})$. Proteins were visualized using ECL following incubation with HRP-conjugated secondary

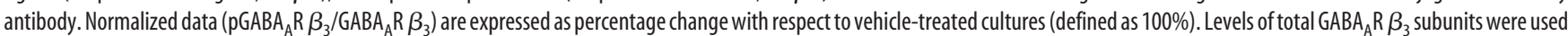
as internal control. $n=4-6$ experiments; ${ }^{*} p<0.05,{ }^{* *} p<0.01$. $B$, Cell-surface levels of $G_{A B A} A_{A}$ s measured using ELISA assays with GABA $A_{A} R \beta_{2 / 3}$ subunit-specific antibody in neurons treated with CR-proBDNF alone (25 ng, $30 \mathrm{~min}$ ) with CR-proBDNF in the presence of ROCKi (CR-proBDNF + ROCKi; $50 \mu \mathrm{m})$, or with ROCKi alone (50 $\mu \mathrm{m})$, and expressed as a (Figure legend continues.) 
proBDNF no longer induced a decrease of the pPTEN/PTEN ratio $(102.6 \pm 14.2 \%$ compared with control, $p=0.401, n=5$; Fig. 5 C).

These results suggest a signaling mechanism in which proBDNF binding to $\mathrm{p} 75^{\mathrm{NTR}}$ activates the RhoA-ROCK-PTEN pathway, which negatively regulates phosphorylation levels and membrane expression of $\mathrm{GABA}_{\mathrm{A}} \mathrm{Rs}$.

To determine whether dephosphorylated receptors are indeed endocytosed, we next measured, by Western blotting, the level of a marker protein for early endosomes (EEA1) on neuronal lysates. We found that activation of $\mathrm{p} 75^{\mathrm{NTR}}$ signaling by CR-proBDNF significantly increases the amount of EEA1 proteins compared with control nonstimulated neurons (140.3 \pm $7.8 \%$ compared with control, $p=0.013 ; n=5$, Fig. $5 D)$. This effect was abolished in the presence of TAT-pep5 $(84.8 \pm 8.5 \%$ compared with control, $p=0.378, n=5$; Fig. $5 D$ ). We then wanted to confirm the presence of internalized receptors in the endosomal compartment by quantifying colocalization of $\mathrm{GABA}_{\mathrm{A}} \mathrm{R} \beta_{2 / 3}$ subunits with EEA1. After 30 min treatment with CR-proBDNF (25 ng/ml), internalized $\mathrm{GABA}_{\mathrm{A}} \mathrm{R} \beta_{2 / 3}$ subunits colocalized extensively in a punctate pattern with EEA1 (184.5 \pm $20.5 \%$ of control nonstimulated cultures, $p=0.0003 ; 35$ neurons analyzed, $n=4$; Fig. $5 E, F)$. The colocalization of $\mathrm{GABA}_{\mathrm{A}} \mathrm{R} \beta_{2 / 3}$ subunits with EEA1 is blocked when CR-proBDNF is applied in the presence of TAT-pep5 (100.6 $\pm 16.5 \%$ of control nonstimulated cultures, $p=0.497, n=35$ neurons analyzed; $n=4$; Fig. $5 E, F)$.

After endocytosis, internalized proteins can be sorted into various compartments, which go through a recycling endosomal pathway or lysosomal degradation pathway (Jacob et al., 2008; Luscher et al., 2011). To determine the contribution of lysosomal degradation in the diminution of cytoplasmic $\mathrm{GABA}_{\mathrm{A}} \mathrm{R} \beta_{2 / 3}$ levels observed in aprotinin (Fig. 2), cultures were treated with aprotinin in the presence of the lysosomal protease inhibitor leupeptin $(5 \mu \mathrm{g} / \mathrm{ml})$. ELISA experiments show that in the presence of leupeptin, aprotinin still induced a decrease in cellsurface expression of the $\beta_{2 / 3}$ subunits (76.7 $\pm 3.1 \%$ compared with control; $p=0.009, n=9$; Fig. $5 G$ ), but significantly dimin-

\footnotetext{
$\leftarrow$

(Figure legend continued.) percentage of vehicle-treated controls. C, CR-proBDNF decreases the phosphorylation of T366 in the PTEN (pPTEN). Total cellular proteins were analyzed using Western blot with polyclonal PTEN and PPTEN antibodies. Hippocampal neurons were treated with vehicle (CTR), CR-proBDNF (25 ng, 30 min), CR-proBDNF plus ROCKi (CR-proBDNF + ROCKi; 50 $\mu \mathrm{m})$, or ROCKi alone $(50 \mu \mathrm{m})$. Proteins were visualized using ECL following incubation with HRP-conjugated secondary antibody. Normalized data (pPTEN/PTEN) are expressed as percentage change with respect to vehicle-treated cultures (defined as 100\%). Levels of total PTEN were used as internal control. $n=5$ experiments; ${ }^{*} p<0.05$. $\boldsymbol{D}$, Neurons were permeabilized and immunolabeled with anti-GABA $R \beta_{2 / 3}$ subunit-specific antibody (green), anti-EEA1 rabbit polyclonal antibody (red), and anti-MAP2 chicken polyclonal antibody (blue) to reveal the intracellular distribution of these proteins. GABA $\mathrm{R} \beta_{2 / 3}$ subunits and EEA1 colocalization appear yellow in merge panels (right). Scale bar, $20 \mu \mathrm{m}$. $\boldsymbol{E}$, The percentage of $\beta_{2 / 3}$ subunitpositive clusters that colocalized with EEA1 puncta/intracellular MAP2 fluorescence ratio was significantly increased in cultures treated with (R-proBDNF $(25 \mathrm{ng}, 30 \mathrm{~min})$. Thirty-five neurons analyzed per condition, $n=4$; ${ }^{* *} p<0.001$. $\boldsymbol{F}$, Western blot analysis with the antibody to EEA1. EEA1 expression was upregulated after treatment with CR-proBDNF (25 ng, $30 \mathrm{~min})$. Proteins were visualized using ECL following incubation with HRP-conjugated secondary antibody. Normalized data (EEA1/ $\beta$-Tubulin) are expressed as percentage change with respect to vehicle-treated cultures (defined as 100\%). $n=5$ experiments; ${ }^{*} p<0.05$. G, Cell-surface levels of $G A B A_{A} R s$ measured using ELISA assays with $G A B A_{A} R \beta_{2 / 3}$ subunit-specific antibody in neurons treated with aprotinin (Apro; $3 \mu \mathrm{g} / \mathrm{ml}, 12 \mathrm{~h}$ ) in the presence or absence of leupeptine $(5 \mu \mathrm{g} / \mathrm{ml})$, or with leupeptine alone $(5 \mu \mathrm{g} / \mathrm{ml})$, and expressed as a percentage of vehicletreated controls (CTR). $\boldsymbol{H}$, Total GABA $R \beta_{A}$ subunit expression normalized to control nontreated conditions. $n=9 ;{ }^{* *} p<0.01,{ }^{* * *} p<0.001$.
}

ished the aprotinin-induced reduction in the cytoplasmic levels of $\mathrm{GABA}_{\mathrm{A}} \mathrm{R} \beta_{2 / 3}(p=0.0004$ compared with aprotinin alone, $n=$ 9; Fig. $5 H$ ). During treatments with aprotinin and in the presence of leupeptin, the cytoplasmic levels of $\beta_{2 / 3}$ subunits remain reduced $(81.0 \pm 2.6 \%$ compared with control; $p=0.004, n=9$; Fig. $5 F$ ), suggesting the inhibition of $\mathrm{GABA}_{\mathrm{A}} \mathrm{R} \beta_{2 / 3}$ synthesis, mediated by $\mathrm{p} 75^{\mathrm{NTR}}$ (Fig. $2 \mathrm{H}$ ).

Together, our results demonstrate that the proBDNF/ p $75^{\text {NTR }} /$ Rho-ROCK signaling pathway triggers a dephosphorylation of $\beta_{3}$ subunits containing $\mathrm{GABA}_{\mathrm{A}} \mathrm{Rs}$, followed by endocytosis and lysosomal degradation of $\mathrm{GABA}_{\mathrm{A}} \mathrm{Rs} \beta_{2 / 3}$.

\section{ProBDNF has no effect on phospho-CREB activation but induces ICER expression via the JAK2/STAT3 signaling cascade}

BDNF plays a critical role in regulating gene expression by activation of different downstream signaling pathways, which most commonly leads to the phosphorylation of CREB (Ghosh et al., 1994; Hu et al., 2008; Lund et al., 2008). pCREB dimerizes and binds to cAMP response element (CRE) motifs to initiate gene transcription (Zhang et al., 2005; Grabenstatter et al., 2012). To determine whether proBDNF can bind to TrkB, we used an indirect approach based on an increase in BDNF/TrkB/ERKdependent pCREB (Ghosh et al., 1994; Kuczewski et al., 2008a). We tested whether the addition of CR-proBDNF or aprotinin induces an increase in PCREB immunoreactivity in MAP2positive neurons. Hippocampal neuronal cultures were stimulated, and the immunofluorescence ratio between PCREB and CREB was quantified. Application of CR-proBDNF does not lead to the phosphorylation of CREB ( $p=0.128,45$ neurons analyzed, $n=4$; Fig. $6 A, B)$. We observed that the addition of mBDNF during application of CR-proBDNF induces a significant increase in the levels of pCREB ( $350 \pm 11 \%$ compared with control; $p=0.0001,45$ neurons analyzed, $n=4$; Fig. $6 A, B)$. This increase was prevented by K252a, demonstrating that under these conditions, only the mature form of BDNF activates TrkB ( $p=$ $0.161,45$ neurons analyzed, $n=4$; Fig. $6 A, B)$. This result further shows that the proBDNF-p75 ${ }^{\text {NTR }}$ pathway does not interfere with TrkB or its downstream signaling pathway.

Alternatively, CRE can be regulated by other CREB isoforms, such as cAMP response element modulator (CREM) and ICER. ICER can homodimerize or heterodimerize with CREB and downregulate the action of CREB (Molina et al., 1993; Lund et al., 2008; Grabenstatter et al., 2012). Therefore, we next determined whether induction of ICER might occur in response to proBDNF treatment and contribute to the repression of $\mathrm{GABA}_{\mathrm{A}} \mathrm{R} \beta_{3}$ synthesis. Hippocampal neuronal cultures were incubated with CR-proBDNF (30 min) in the presence or absence of TAT-pep5. Immunohistochemistry using the CREM1 (ICER) antibody, in combination with anti-MAP2 antibody, was performed. To normalize the results obtained between different cultures, the ICER/ MAP2 intensity ratio was quantified. Relative to control neurons, CR-proBDNF treatment significantly increased the expression of ICER $(152.3 \pm 7.4 \%, p=0.0004$, compared with control; 45 neurons analyzed, $n=4$; Fig. $6 C, D)$. This increase of ICER was completely blocked by TAT-pep5 $(104.7 \pm 6.4 \%, p=0.099$, compared with control; 45 neurons analyzed, $n=4$; Fig. $6 C, D$ ). In contrast, after $12 \mathrm{~h}$ treatment with CR-proBDNF, ICER no longer increased and returned to control levels $(110.1 \pm 8.2 \%$, $p=0.065$, compared with control; 45 neurons analyzed, $n=4$; Fig. $6 C, D)$.

To confirm the transient increase of ICER proteins after exposition to CR-proBDNF, Western blotting analysis was per- 

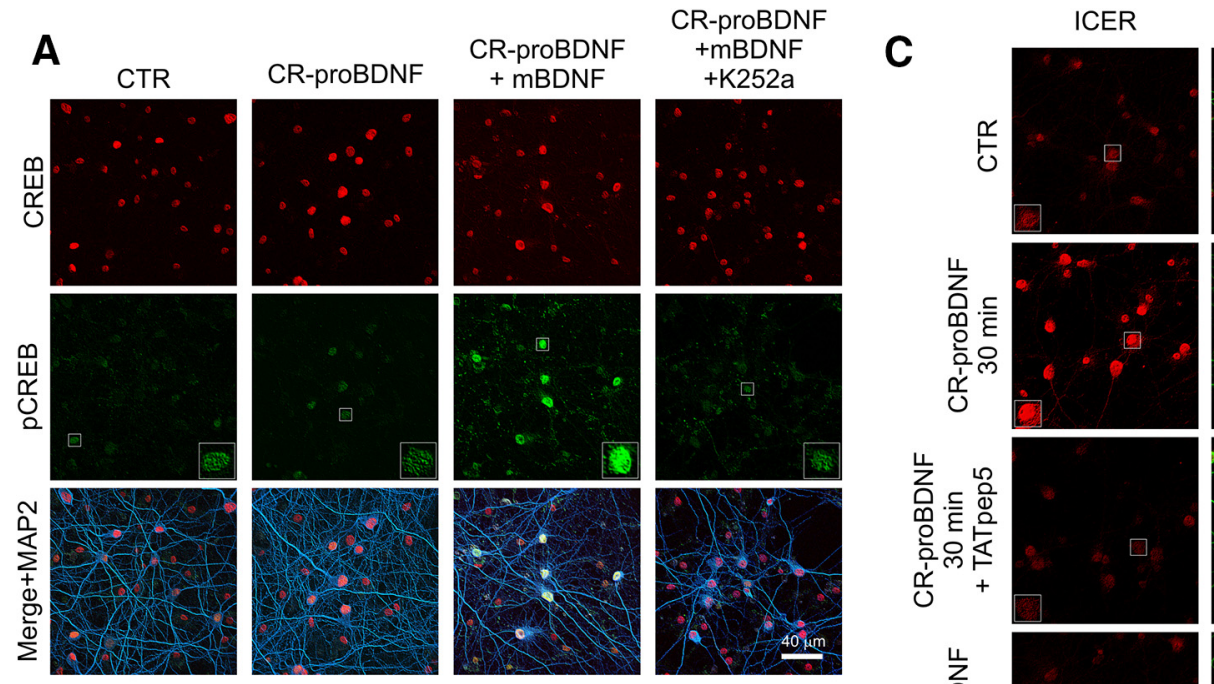

ICER+ MAP2
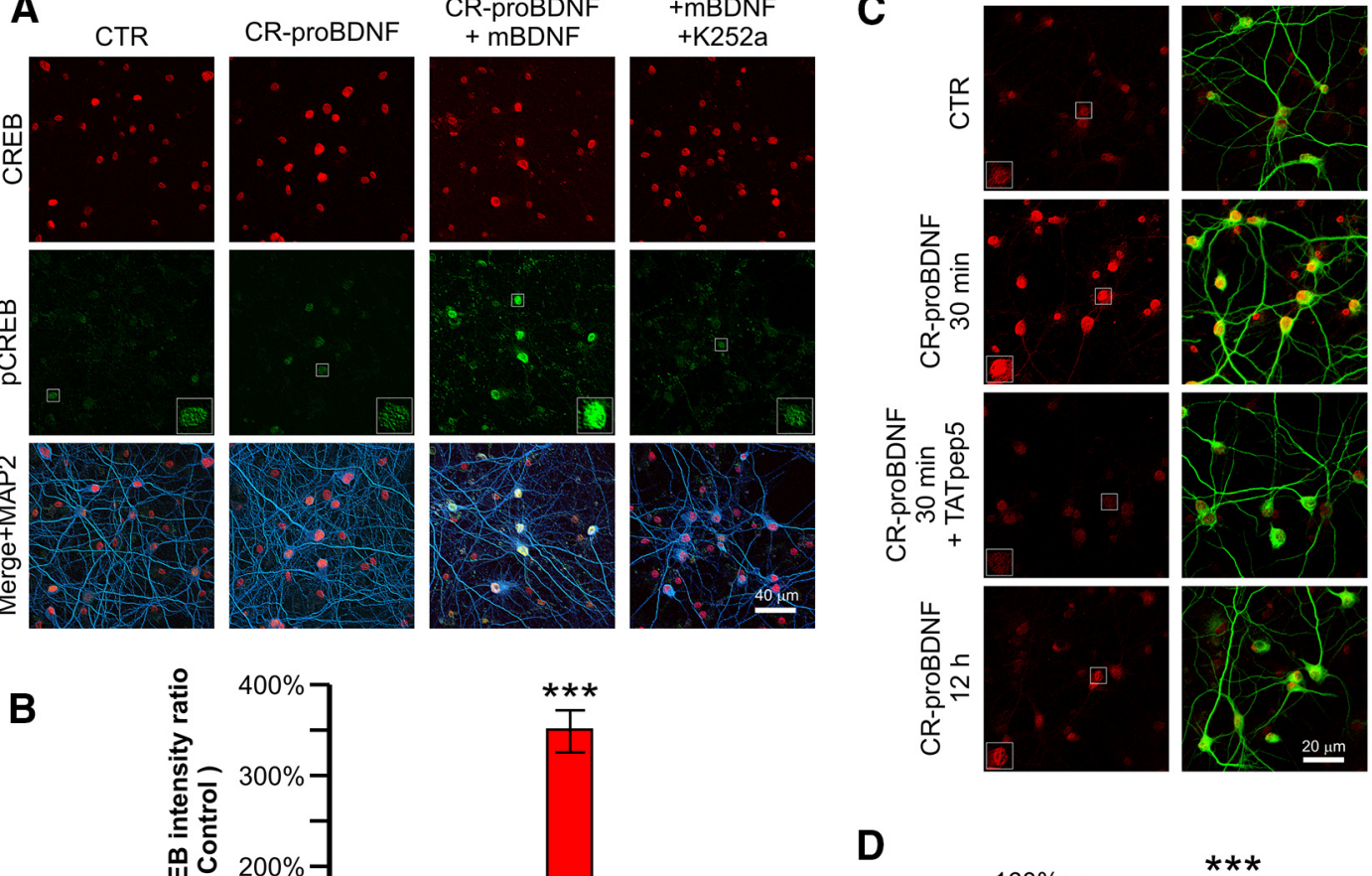

D
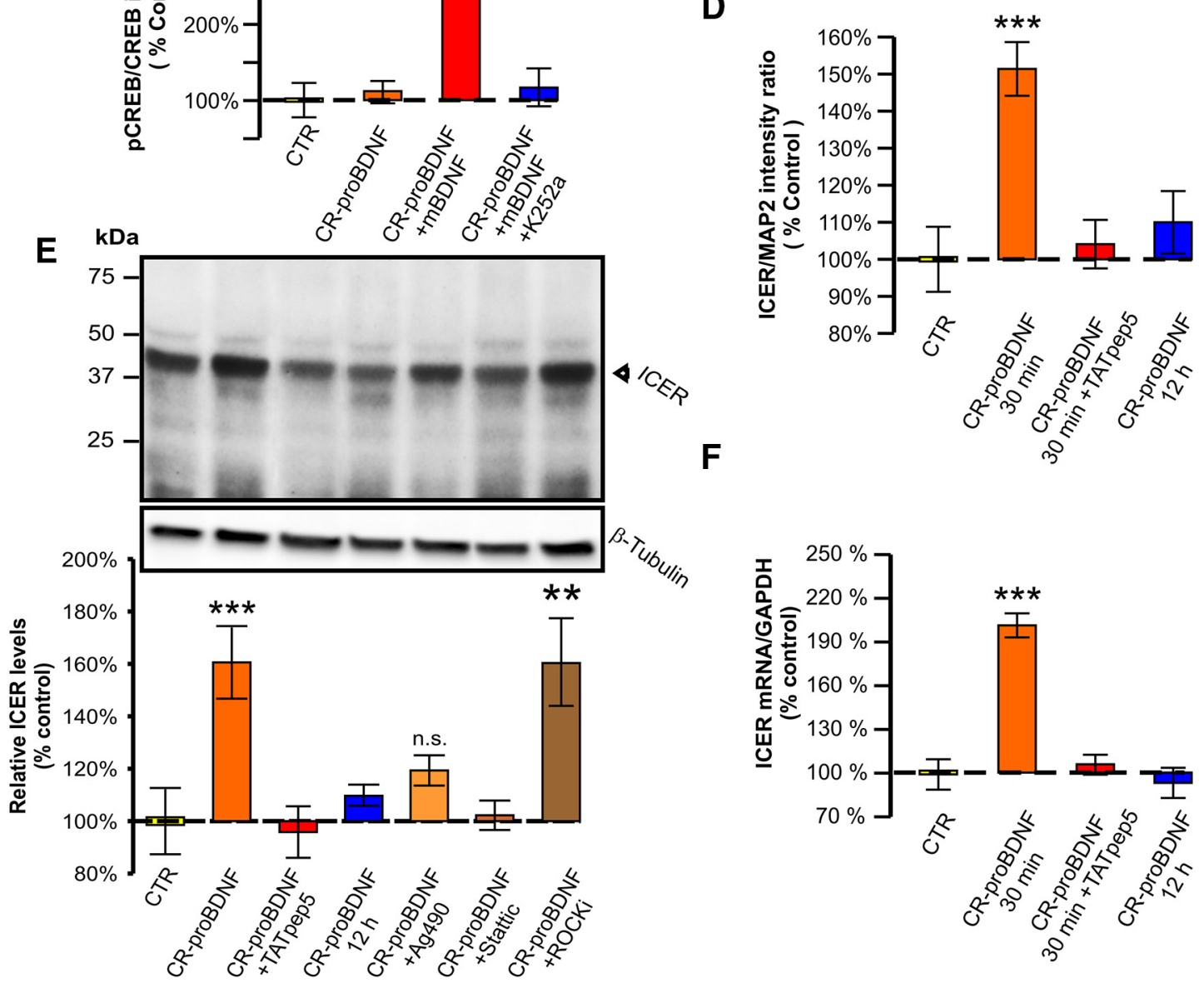

Figure 6. ProBDNF has no effect on phospho-CREB activation but induces ICER expression via the JAK2/STAT3 signaling cascade. $A$, Immunofluorescence signal of CREB (red, top), pCREB (green, middle) in hippocampal neurons in control conditions (CTR), or treated with (R-proBDNF alone (25 ng; (R-proBDNF), or CR-proBDNF plus mBDNF (CR-proBDNF + mBDNF; $25 \mathrm{ng}$ ), or CR-proBDNF plus $\mathrm{mBDNF}$ in the presence of K252a (CR-proBDNF + mBDNF + K252a; $200 \mathrm{~nm}$ ). Right, Merged images with MAP2 staining (blue). Scale bar, $40 \mu \mathrm{m}$. $\boldsymbol{B}$, Average ratio of pCREB/CREB in the different conditions normalized to control. $n=15$ neurons analyzed per treatment in $n=3$ independent experiments; ${ }^{* * *} p<0.001$. C, Immunofluorescence signal of ICER (red; top) in hippocampal neurons in control conditions (CTR), or treated with CR-proBDNF (25 ng) for $30 \mathrm{~min}$ (CR-proBDNF $30 \mathrm{~min}$ ), for $12 \mathrm{~h}$ (CR-proBDNF $12 \mathrm{~h}$ ), or for $30 \mathrm{~min}$ in the presence of TAT-pep5 (CR-pro-BDNF $30 \mathrm{~min}+$ TATpep5; $2 \mu \mathrm{M}$ ), following a costaining with anti-MAP2 chicken polyclonal antibody (green; bottom) to reveal neuronal cells. Scale bar: $20 \mu \mathrm{m}$. D, Average fluorescence intensity ratio of ICER/MAP2 in the different conditions normalized to control. Forty-five neurons analyzed per condition, $n=4 ;{ }^{* * *} p<0.001$. E. Western blot analysis with the antibody to ICER. ICER expression was upregulated after acute treatment with CR-proBDNF ( $25 \mathrm{ng}, 30 \mathrm{~min}$ ) but not with chronic application of CR-proBDNF ( $25 \mathrm{ng}, 12 \mathrm{~h}$ ). The increase of ICER was antagonized by TAT-pep5 ( $2 \mu \mathrm{m}$ ), AG490 $(50 \mu \mathrm{M})$, and Stattic $(10 \mu \mathrm{M})$. This increase was insensitive to ROCKi $(50 \mu \mathrm{M})$. Proteins were visualized using ECL following incubation with HRP-conjugated secondary (Figure legend continues.) 
formed on neuronal lysates. We found that activation of the p $75^{\text {NTR }}$ pathway by CR-proBDNF treatment induces an increase in the total amount of ICER proteins $(160.68 \pm 13.4 \%, p=$ 0.0002 , compared with control; $n=6$; Fig. $6 E$ ). This effect was antagonized with TAT-pep5 $(94.0 \pm 10.7 \%, p=0.237$, compared with control; $n=6$; Fig. $6 E$ ). Treatment of neuronal cell cultures with CR-proBDNF (12 h) or TAT-pep5 alone did not produce any detectable effect on ICER protein levels (Fig. 6E). Previous studies have shown that BDNF activates the JAK2/ STAT3 signaling cascade, which in turn drives ICER expression (Lund et al., 2008; Grabenstatter et al., 2014). In our study, we investigated the JAK2/STAT3 and RhoA-ROCK pathways in an attempt to isolate downstream signaling proteins interacting with p $75^{\text {NTR }}$ and identify potential cell-specific proBDNF/p $75^{\text {NTR }}$ related mechanisms responsible for ICER induction. The CRproBDNF/P75 ${ }^{\mathrm{NTR}}$-dependent increases in ICER level was significantly attenuated by AG490 (119.62 $\pm 5.9 \%$ of control nonstimulated cultures, $p=0.484, n=4$; Fig. $6 E$ ) and Stattic $(102.07 \pm 5.0 \%$ of control nonstimulated cultures, $p=0.288$, $n=4$; Fig. $6 E$ ). Interestingly, this increase was insensitive to ROCKi ( $160.84 \pm 16.9 \%$ of control nonstimulated cultures, $p=$ $0.005, n=4$; Fig. $6 E$ ).

To investigate whether proBDNF/p $75^{\mathrm{NTR}}$ pathway would also regulate ICER gene expression, ICER mRNA levels were measured using qRT-PCR. As illustrated in Figure $6 F$, acute treatment with CR-proBDNF shows a robust increase of ICER mRNA levels (202.1 $\pm 7.4 \%, p=0.0004$, compared with control; $n=6)$, which returned to basal levels after $12 \mathrm{~h}$ treatment with proBDNF $(97.2 \pm 9.8 \%, p=0.381$, compared with control; $n=6$; Fig. $6 F)$ with kinetics similar to those of ICER proteins. This increase was blocked by TAT-pep5 $(105.3 \pm 4.7 \%, p=0.437$, compared with control; $n=6$; Fig. $6 F$ ).

Thus, these data show that ICER is induced in neuronal cultures by proBDNF/p7 ${ }^{\text {NTR }}$ signaling via the JAK2/STAT3 pathway. Moreover, induction of ICER following activation of the p75 ${ }^{\text {NTR }}$ pathway precedes the downregulation of $\mathrm{GABA}_{\mathrm{A}} \mathrm{R} \beta_{3}$ gene expression, suggesting that ICER might be a repressor of $\mathrm{GABA}_{\mathrm{A}} \mathrm{R} \beta_{3}$ transcription.

\section{Treatment with proBDNF induced upregulation of p75 ${ }^{\text {NTR }}$ expression}

So far, we have shown that the consequence of treatment with CR-proBDNF or aprotinin is mediated by $\mathrm{p} 75^{\mathrm{NTR}}$ activation. To further investigate the role of $\mathrm{p} 75^{\mathrm{NTR}}$ in GABAergic downregulation, we next wanted to determine whether treatment of cultures with proBDNF influenced the levels of $\mathrm{p} 75^{\mathrm{NTR}}$ expression.

Hippocampal neuronal cultures were incubated with aprotinin in the presence or absence of TAT-pep5. Immunohistochemistry using an antibody against $\mathrm{p} 75^{\mathrm{NTR}}$, which recognizes the extracellular domain of the receptor, in combination with anti-MAP2 antibody was performed. To normalize the results obtained between different cultures, the p $75^{\text {NTR }} / \mathrm{MAP} 2$ intensity ratio was quantified. Relative to control neurons, treatment with

\footnotetext{
(Figure legend continued.) antibody. Normalized data (ICER/ $\beta$-Tubulin) are expressed as percentage change with respect to vehicle-treated cultures (defined as $100 \%$ ). $n=4-6$ experiments; ${ }^{* *} p<0.01,{ }^{* * *} p<0.001$. $\boldsymbol{F}$, Relative expression of ICER mRNA transcripts in neurons treated with CR-proBDNF for 30 min (CR-proBDNF $30 \mathrm{~min}$ ), with CR-proBDNF for $12 \mathrm{~h}$ (CR-proBDNF $12 \mathrm{~h} ; 25 \mathrm{ng}$ ), or with CR-proBDNF plus TAT-pep5 for $30 \mathrm{~min}$ (CR-proBDNF $30 \mathrm{~min}$ + TATpep5; $2 \mu \mathrm{M}$ ), and expressed as a percentage of vehicle-treated controls (CTR). ICER gene expression was normalized to the expression of the housekeeping gene, GAPDH, in the same RNA preparation. $n=6 ;^{* * *} p<0.001$.
}

aprotinin significantly increased the expression of $\mathrm{p} 75^{\mathrm{NTR}}$ (210.7 $\pm 14.9 \%, p=0.0001$, compared with control; 35 neurons analyzed, $n=4$; Fig. $7 A, B)$. This effect was abolished by application of TAT-pep5 before treatment with aprotinin (62.3 \pm $18.2 \%, p=0.159$, compared with control; 35 neurons analyzed, $n=4$; Fig. $7 A, B)$.

To confirm the increase of $\mathrm{p} 75^{\mathrm{NTR}}$ proteins after treatment with aprotinin, Western blotting analysis was performed on hippocampal neuronal lysates. We found that aprotinin induces an increase in the total amount of $\mathrm{p} 75^{\mathrm{NTR}}$ proteins $(159.17 \pm 19.6 \%$, $p=0.046$, compared with control; $n=4$; Fig. $7 C)$. This effect was antagonized with TAT-pep5 (Fig. 7C). Incubation of neuronal cells with TAT-pep5 alone did not differ from that of control samples (Fig. 7C).

To further investigate whether proBDNF would also regulate $\mathrm{p} 75^{\mathrm{NTR}}$ gene expression, $\mathrm{p} 75^{\mathrm{NTR}}$ mRNA levels were measured using qRT-PCR. As illustrated in Figure $7 D$, treatment with aprotinin shows a significant increase of $\mathrm{p} 75^{\mathrm{NTR}} \mathrm{mRNA}$ levels (165.4 $\pm 5.1 \%, p=0.008$, compared with control; $n=6$; Fig. 7D).

Thus the present data indicate that treatment with aprotinin triggers the activation of $\mathrm{p} 75^{\mathrm{NTR}}$ gene expression. This increase in p $75^{\text {NTR }}$ mRNAs is followed by an upregulation of $\mathrm{p} 75^{\text {NTR }}$ protein levels. This positive feedback loop might reinforce the action of proBDNF.

\section{Endogenous accumulation of proBDNF in vivo decreases GABAergic synaptic activity}

We next placed our observations obtained on cell cultures in an integrated context by determining whether endogenous accumulation of proBDNF could lead to a deficit of GABAergic activity in vivo. For this purpose, we performed intracerebroventricular injection of tPA-Stop, an inhibitor of proteolytic processing of proBDNF in mBDNF by plasminogen (Bozdagi et al., 2008) at P0. Two days after injection, $\mathrm{GABA}_{\mathrm{A}} \mathrm{R}$ mIPSCs were recorded under whole-cell voltage clamp $\left(V_{\mathrm{h}}=-70 \mathrm{mV}\right)$ from rat CA3 pyramidal neurons. These data were then compared with those obtained from control animals. GABA $\mathrm{A}$ mIPSCs recorded from hippocampi treated with tPA-Stop exhibited a striking difference in mIPSC interevent intervals $(9.69 \pm 0.84 \mathrm{~s}$ in tPA-STOP, 13 neurons analyzed, $n=5$; $p<0.001)$ and amplitude $(41.35 \pm 4.2 \mathrm{pA}$ in tPA-Stop, 13 neurons analyzed, $n=5$; $p<0.001)$ compared with controls $(2.92 \pm 0.17 \mathrm{~s}$ and $64.25 \pm 8.3$ pA in controls 13 neurons analyzed, $n=5$; Fig. $8 A-C)$. The kinetic properties of $\mathrm{mGABA}_{\mathrm{A}}$ PSCs were unchanged (Fig. $8 D, E)$. The membrane capacitance of the recorded cells was not different between control and tPA-Stop hippocampi $(23.42 \pm 4.8$ $\mathrm{pF}$ in control vs $22.08 \pm 5.5 \mathrm{pF}$ in tPA-Stop; $p=0.262$ ). We next determined whether the treatment with $\mathrm{tPA}$-Stop leads to a decrease in $\mathrm{GABA}_{\mathrm{A}} \mathrm{R}$ phosphorylation levels and an upregulation of $\mathrm{p} 75^{\mathrm{NTR}}$ similar to those observed in cell cultures. To this end, we measured, by Western blotting, the phosphorylation state of $\mathrm{GABA}_{\mathrm{A}} \mathrm{R} \beta_{3}$ subunits and the level of $\mathrm{p} 75^{\mathrm{NTR}}$ proteins. Our results showed that treatment with tPA-Stop decreases the phosphorylation state of $\mathrm{GABA}_{\mathrm{A}} \mathrm{R} \beta_{3}$ subunits $(63.80 \pm 13.5 \%$ of control nonstimulated hippocampi, $p=0.017, n=5$; Fig. $8 F)$ and upregulates the total amount of $\mathrm{p} 75^{\mathrm{NTR}}$ proteins $(225,74 \pm$ $58.1 \%, p=0.029$, compared with control; $n=5$; Fig. $8 G)$. Therefore, these results are in agreement with those obtained in cultures showing that endogenous proBDNF in vitro and in vivo downregulates GABAergic synaptic activity, inhibits the phosphorylation levels of $\mathrm{GABA}_{\mathrm{A}} \mathrm{R} \beta_{3}$ subunits, and increases $\mathrm{p} 75^{\mathrm{NTR}}$ expression. 
A
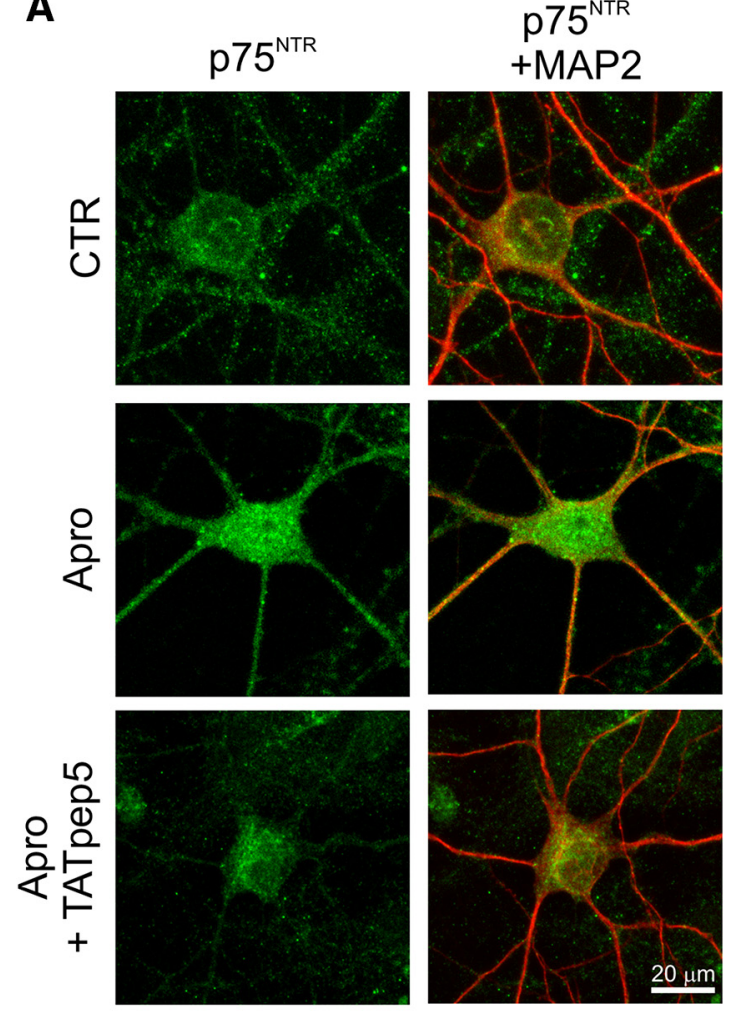

C

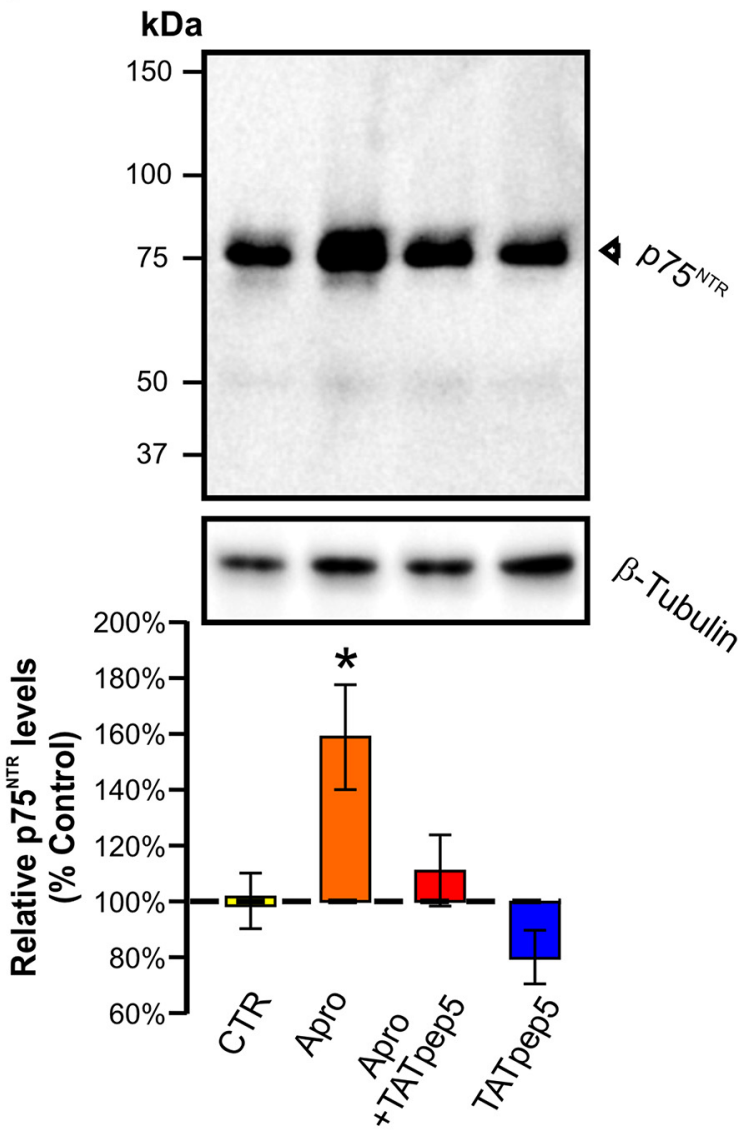

B

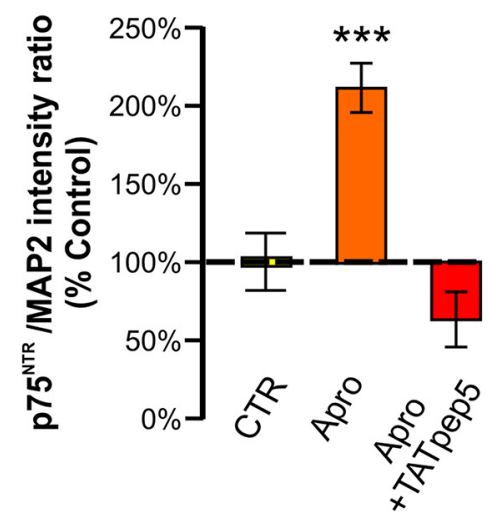

D

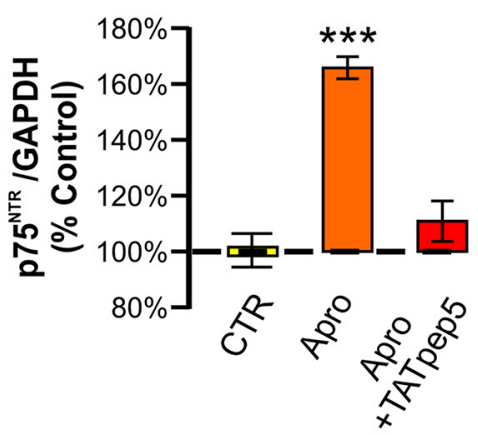

Figure 7. $\quad p 75^{\text {NTR }}$ is upregulated upon chronic treatment with aprotinin. $A$, Cultured neurons (14 DIV), in control conditions (CTR), or treated with aprotinin in the absence of TAT-pep5 (Apro; $3 \mu \mathrm{g} / \mathrm{ml}, 12 \mathrm{~h}$ ) or with aprotinin in the presence of TAT-pep5 (Apro + TATpep5; $2 \mu \mathrm{M}$ ) and immunolabeled with p $75^{\text {NTR }}$-specific rabbit polyclonal antibody (green; left), following a costaining with anti-MAP2 chicken polyclonal antibody (red; right) to reveal neuronal cells. Scale bar, $20 \mu \mathrm{m}$. B, Average fluorescence intensity ratio of p $75^{\mathrm{NTR}} / \mathrm{MAP2}$ in the different conditions normalized to control (CTR). $n=35$ neurons analyzed per condition, per experiment; $n=4 ;{ }^{* * *} p<0.001$. C, Western blot analysis with the antibody to $p 75^{\text {NTR }}$. p $75^{\text {NTR }}$ expression was upregulated after treatment with aprotinin (Apro; $3 \mu \mathrm{g} / \mathrm{ml}, 12 \mathrm{~h}$ ). This increase was blocked by TAT-pep5. Proteins were visualized using ECL following incubation with HRP-conjugated secondary antibody. Normalized data ( $\mathrm{p} 75^{\mathrm{NTR}} / \beta$-Tubulin) are expressed as percentage change with respect to vehicle-treated cultures (defined as $\left.100 \%\right) . n=4$ experiments; ${ }^{*} p<0.05$. D, Relative expression of $\mathrm{p} 75^{\mathrm{NTR}} \mathrm{mRNA}$ transcripts in neurons treated with aprotinin in the absence of TAT-pep 5 (Apro; $\left.3 \mu \mathrm{g} / \mathrm{ml}, 12 \mathrm{~h}\right)$, or with aprotinin in the presence of TAT-pep5 (Apro + Tatpep5; $2 \mu \mathrm{M}$ ), and expressed as a percentage of vehicle-treated controls (CTR). p75 ${ }^{\text {NTR }}$ gene expression was normalized to the expression of the housekeeping gene, GAPDH, in the same RNA preparation. $n=6$; ${ }^{* *} p<0.001$.

\section{Discussion}

BDNF is initially expressed in a precursor form (proBDNF) and is cleaved to form $\mathrm{mBDNF}$. While the regulatory role of BDNF on the expression and membrane turnover of GABA receptors is well established, the proBDNF- $\mathrm{GABA}_{\mathrm{A}} \mathrm{R}$ relationship remains obscure. Here, using developing hippocampal neuronal cultures and immature ex vivo acute hippocampal slices, we show that the activation of p $75^{\text {NTR }}$ downregulates GABAergic synaptic transmission. Whether decrease of synaptic contacts is induced by proBDNF or secondary to the loss of surface $\mathrm{GABA}_{\mathrm{A}}$ Rs remained to be determined. We further provided evidence that the downregulation of GABAergic transmission relies on the activation of 
A

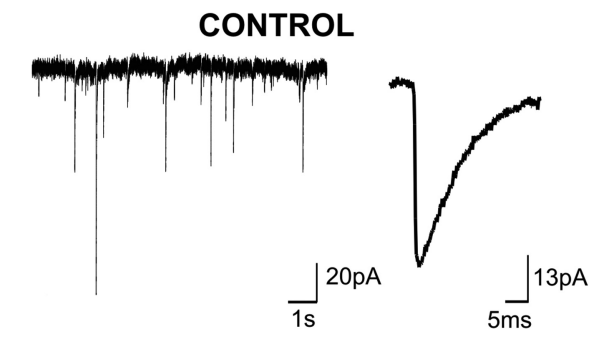

tPA-STOP

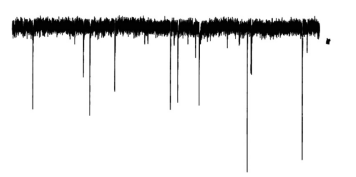

$\frac{1}{1 \mathrm{~s}}^{20 \mathrm{pA}}$

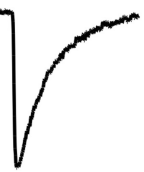

$\underset{5 \mathrm{~ms}}{\rfloor} 13 \mathrm{pA}$
B

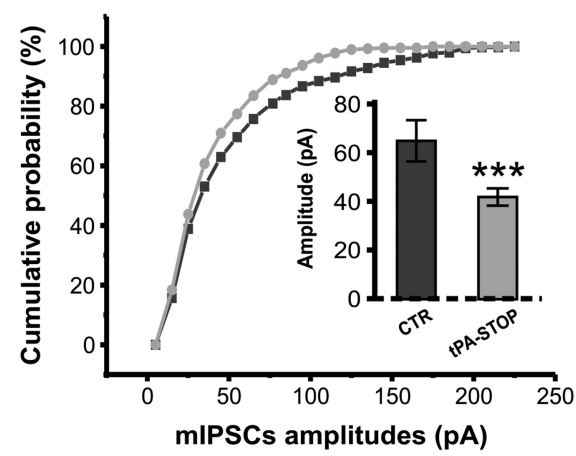

C

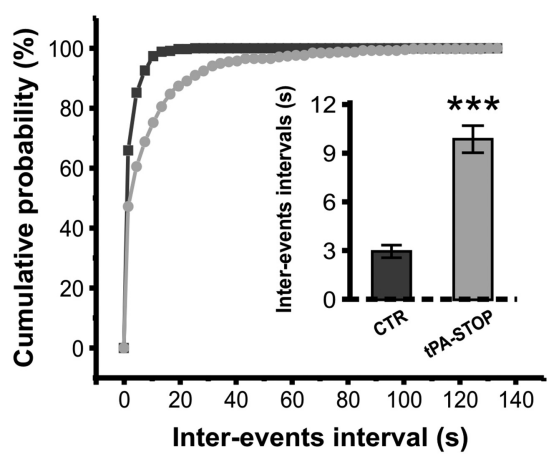

D

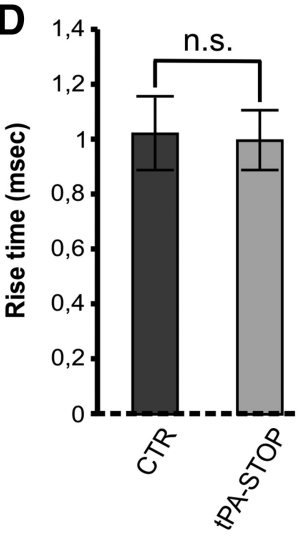

E

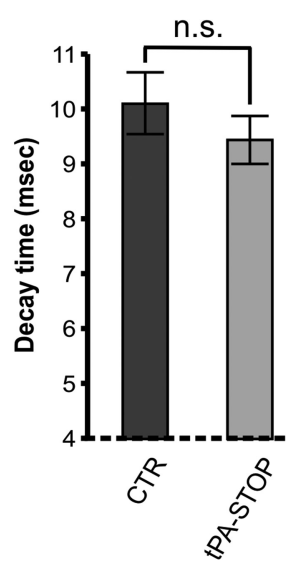

F

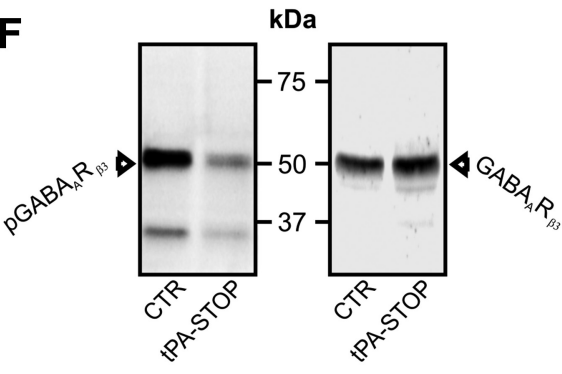

G

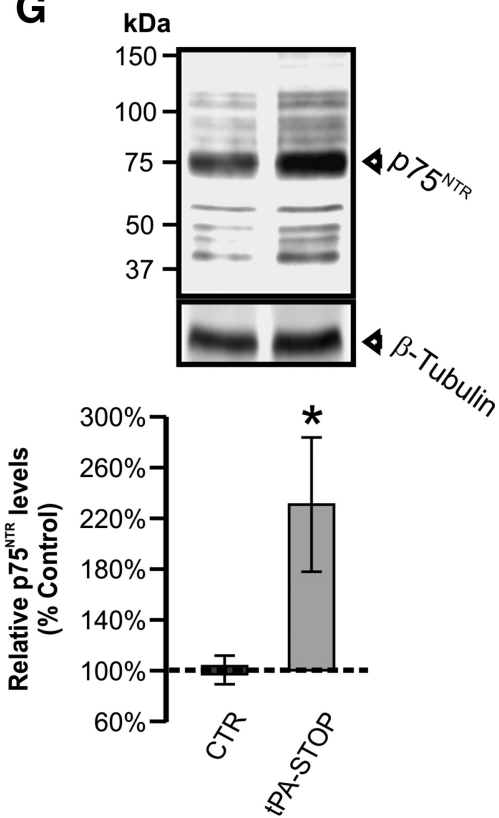

Figure 8. In vivo tPA-Stop injection decreases GABAergic synaptic activity. $A$, Upper traces, Representative recordings of GABA $A_{A}$ mIPSCs illustrating the decrease in events frequency and amplitude after intracerebroventricular injection of tPA-Stop at postnatal day 0 . Average mGABA PSCs are shown at a higher scale. $\boldsymbol{B}, \boldsymbol{C}$, Cumulative distributions of mIPSC amplitudes and interevent intervals. Insets in $\boldsymbol{B}$ and $\boldsymbol{C}$ displayt the mean \pm SEM amplitude and interevent intervals respectively (Kolmogorov-Smirnov test, ${ }^{* * *} p<0,001$ for amplitude and interevent interval). $\boldsymbol{D}, \boldsymbol{E}$, Rise time $(\boldsymbol{D})$ and decay time $(\boldsymbol{E}) \cdot n=13$ neurons per condition. $\boldsymbol{F}$, In vivo tPA-Stop administration decreases the phosphorylation of Ser408/409 in the $G A B A_{A} R \beta_{3}$ subunit $\left(\mathrm{DGABA}_{A} \mathrm{R} \beta_{3}\right)$. Total cellular proteins were analyzed using Western blot with polyclonal $G A B A_{A} R \beta_{3}$ subunit and $p G A B A_{A} R \beta_{3}$ subunit antibodies. Proteins were visualized using ECL following incubation with HRP-conjugated secondary antibody. Normalized data $\left(p G A B A_{A} R \beta_{3} / G A B A_{A} R \beta_{3}\right)$ are expressed as percentage change with respect to vehicle-treated animals (defined as 100\%). Levels of total $G A B A_{A} R \beta_{3}$ subunits were used as internal control. $n=5$ experiments; ${ }^{*} p<0.05$. $G$, In vivo tPA-Stop administration increases $\mathrm{p} 75^{\mathrm{NTR}}$ expression. Total cellular proteins were analyzed using Western blot with the antibody to $\mathrm{p} 75^{\mathrm{NTR}}$. Proteins were visualized using ECL following incubation with HRP-conjugated secondary antibody. Normalized data (p75 NTR/ $\beta$-Tubulin) are expressed as percentage change with respect to vehicle-treated animals (defined as $100 \%$ ). $n=5$ experiments; ${ }^{*} p<0.05$.

two distinct downstream pathways: a RhoA-ROCK-PTEN pathway leading to dephosphorylation/endocytosis/degradation of $\mathrm{GABA}_{\mathrm{A}} \mathrm{Rs}$, and a JAK2-STAT3-ICER pathway leading to decrease synthesis.
ProBDNF-p $75^{\text {NTR }}$ signaling activates the dephosphorylation and internalization of $\mathrm{GABA}_{\mathrm{A}} \mathrm{Rs}$

$\mathrm{GABA}_{\mathrm{A}} \mathrm{Rs}_{\mathrm{s}}$ constantly cycle between synaptic sites and endocytic structures. The endocytosis/exocytosis of $\mathrm{GABA}_{\mathrm{A}} \mathrm{Rs}$ depends on 


\section{8 proBDNF}

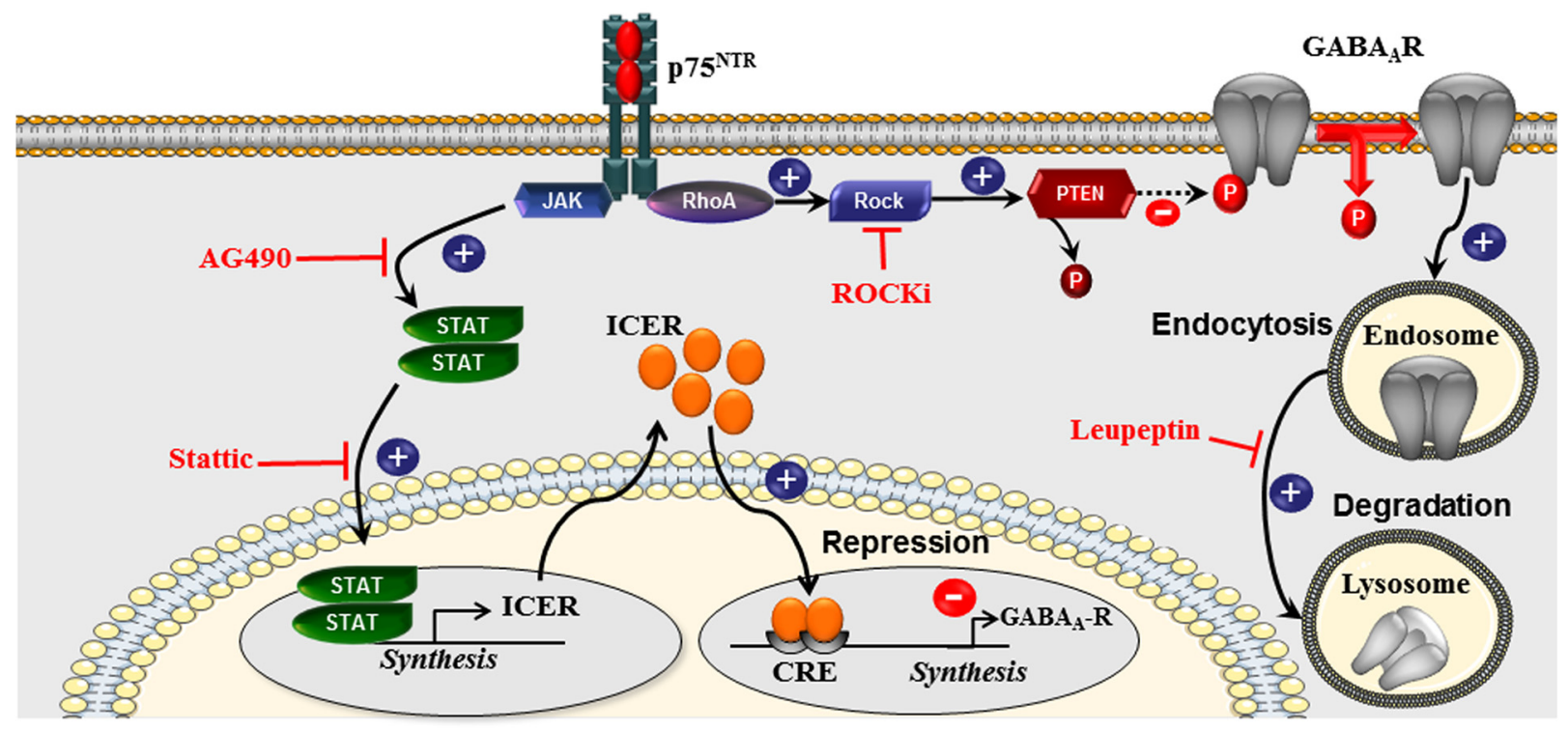

Figure 9. ProBDNF negatively regulates $G A B A_{A} R$ expression. Activation of $p 75^{N T R}$ by proBDNF impairs GABA $A_{A}$ Rs through two distinct pathways: (1) a RhoA/ROCK/PTEN pathway that decreases the phosphorylation levels of $\mathrm{GABA}_{A}$ Rs and thus triggers endocytosis and degradation of internalized receptors; and (2) a JAK2/STAT3/ICER pathway that leads to the repression of GABA $\mathrm{R}_{\mathrm{A}}$ synthesis.

their phosphorylation state (Jovanovic et al., 2004). Dephosphorylation of the $\mathrm{GABA}_{\mathrm{A}} \mathrm{R} \beta_{3}$ at Ser408/409 residues unmasks docking sites with the clathrin AP2 adaptor, which induces the endocytosis of $\mathrm{GABA}_{\mathrm{A}}$ Rs (Brandon et al., 2000; Kittler et al., 2000, 2005, 2008; Jovanovic et al., 2004). Conversely, phosphorylation of the receptors prevents internalization. Thus, it is very likely that the activation of receptor endocytosis by proBDNF described here occurs due to a decrease in $\mathrm{GABA}_{\mathrm{A}} \mathrm{R}$ phosphorylation and the subsequent interaction with the AP2 complex. Accordingly, we found that $\mathrm{p} 75^{\mathrm{NTR}}$ activation leads to a dephosphorylation and internalization of $\mathrm{GABA}_{\mathrm{A}} \mathrm{Rs}$ via the RhoAROCK-PTEN pathway (Fig. 9). Thus, we found that p $75^{\text {NTR }}$ activation leads to a dephosphorylation, and hence an activation of PTEN, and that this effect, as well as the dephosphorylation and internalization of $\mathrm{GABA}_{\mathrm{A}} \mathrm{Rs}$, was abolished by ROCKi. Previous studies indicated that proneurotrophins activate the RhoAROCK pathway and PTEN through p75 ${ }^{\text {NTR }}$ (Gehler et al., 2004; Song et al., 2010). Interestingly, the increase of PTEN activity is followed by a decrease of $\mathrm{GABA}_{\mathrm{A}} \mathrm{R}$ cell-surface expression in hippocampal neurons (Liu et al., 2010). How PTEN dephosphorylates and downregulates $\mathrm{GABA}_{\mathrm{A}} \mathrm{Rs}$ is presently unknown, but may likely implicate the protein phosphatase $2 \mathrm{~A}$ (PP2A), a downstream target of phosphoinositide-3 kinase (Vasudevan et al., 2011 ) involved in the dephosphorylation of $\mathrm{GABA}_{\mathrm{A}} \mathrm{R} \beta_{3}$ (Jovanovic et al., 2004).

In agreement with this, the inhibition of $\mathrm{GABA}_{\mathrm{A}} \mathrm{R}$ endocytosis may involve PI3K-mediated inhibition of PP2A function via TrkB. (Jovanovic et al., 2004; Porcher et al., 2011). BDNF is known to inhibit PTEN and, in contrast, PTEN activated via p75 ${ }^{\text {NTR }}$ can block PI3K (Song et al., 2010), thereby suggesting that PTEN activates the endocytosis of $\mathrm{GABA}_{\mathrm{A}}$ Rs by inhibiting the PI3K signaling pathway. These findings suggest that the endocytosis of $\mathrm{GABA}_{\mathrm{A}}$ Rs could be determined by the competition between TrkB and $\mathrm{p} 75^{\mathrm{NTR}}$ on the PI3K-mediated regulation of PP2A activity via PTEN.
After endocytosis, internalized receptors can be sorted into various compartments, which go through a recycling endosomal or lysosomal degradation pathway (Jacob et al., 2008; Luscher et al., 2011). The observation that leupeptin leads to a cytoplasmic accumulation of internalized $\mathrm{GABA}_{\mathrm{A}}$ Rs indicates that the fate of endocytosed receptors is via the lysosomal pathway, hence leading to a decrease in the total level of $\mathrm{GABA}_{\mathrm{A}}$ Rs. Although we cannot exclude the possible contribution of other proneurotrophins in the effects mediated by aprotinin treatment, our results demonstrate that $\mathrm{p} 75^{\mathrm{NTR}}$ activation downregulates $\mathrm{GABA}_{\mathrm{A}}$ Rs by two different mechanisms and signaling pathways.

All together, the observations obtained here may reflect the functional antagonism between $\mathrm{p} 75^{\mathrm{NTR}}$ and TrkB receptor signaling (Lu, 2003; Yang et al., 2014). BDNF, acting via the TrkB receptor, has different modulatory effects on the efficacy of GABAergic synapses and transmission. BDNF has been shown to increase cell-surface expression of $\mathrm{GABA}_{\mathrm{A}}$ Rs by inhibiting receptor endocytosis, enhancing cell-surface stability (Joshi and Kapur, 2009; Porcher et al., 2011), and promoting GABAergic synaptogenesis (Rico et al., 2002; Elmariah et al., 2004, 2005).

\section{Underlying mechanisms of decreased $\mathrm{GABA}_{\mathrm{A}} \mathrm{R}$ synthesis}

In the current study, we further investigated the subcellular mechanisms triggered by proBDNF at the gene transcription level. The results obtained here indicate that mRNA levels for $\beta_{3}$ subunits of the $\mathrm{GABA}_{\mathrm{A}} \mathrm{R}$ are downregulated in neuronal cultures following treatment with proBDNF. Furthermore, we provided evidence that proBDNF-induced inhibition of $\mathrm{GABA}_{\mathrm{A}} \mathrm{R}$ synthesis relies on a mechanism coupling the $\mathrm{p} 75^{\mathrm{NTR}}$ and JAK2 pathways. This finding sheds light on a critical role of the proBDNF/ p $75^{\mathrm{NTR}} / \mathrm{JAK} 2 / \mathrm{STAT} 3$ cascade in regulating the expression of $\mathrm{GABA}_{\mathrm{A}} \mathrm{R}$ subunits. Interestingly, in a model of epileptogenesis, similar functions had also been described for BDNF in the regulation of different gene transcripts encoding $\mathrm{GABA}_{\mathrm{A}} \mathrm{Rs}$ (Lund et al., 2008). In this model, the authors then demonstrated that the 
seizure-induced decrease in $\mathrm{GABA}_{\mathrm{A}} \mathrm{R} \alpha_{1}$ is mediated by the JAK/ STAT pathway regulated by BDNF. The activation of the BDNF/ JAK/STAT pathway causes an increase in PCREB and ICER, which mediate the repression of $\mathrm{GABA}_{\mathrm{A}} \mathrm{R} \alpha_{1}$ gene transcription through CRE site binding ( $\mathrm{Hu}$ et al., 2008; Lund et al., 2008), where the consensus sequence TGACGTAC is contained (Molina et al., 1993; Grabenstatter et al., 2012). We show that ICER is induced in primary cultured hippocampal neurons after treatment with proBDNF. This induction precedes the decreases of $\mathrm{GABA}_{\mathrm{A}} \mathrm{R} \beta_{3}$ subunits. Whether proBDNF-induced ICER is directly responsible for the repression of $\beta_{3}$ gene expression mRNA still remains to be identified, but the binding CRE motif on $\mathrm{GABA}_{\mathrm{A}} \mathrm{R} \beta_{3}$ promoter has been predicted by the computational analysis of functional CRE (Zhang et al., 2005), suggesting that ICER might directly decrease $\beta_{3}$ subunit mRNA levels.

In our study, the increase in ICER mRNA and protein appear within $1 \mathrm{~h}$ following treatment with proBDNF and returns to baseline within $12 \mathrm{~h}$. ICER is an alternative product of the CREM gene but the increase in ICER mRNA appears to be specific to ICER transcripts. Indeed, proBDNF does not increase the ratio of pCREB/CREB. This result indicates that in our model, ICER expression can be activated in a nondependent CRE manner (Lund et al., 2008). Moreover, it is known that after induction, ICER can compete with CREB for the ICER promoter (Molina et al., 1993), suppressing its own transcription in a negative feedback loop, thus explaining the transient activation of ICER observed here.

\section{Upregulation of $\mathrm{p} 75^{\mathrm{NTR}}$ and pathophysiological consequences}

$\mathrm{P} 75^{\mathrm{NTR}}$ is widely expressed in the developing CNS, with the highest levels during the first postnatal weeks, a time of synapse formation and elimination, and downregulated in the adult brain (Balkowiec and Katz, 2002; Yang et al., 2009). P75 ${ }^{\text {NTR }}$ is also upregulated in pathological conditions, including stroke, ischemia, axotomy, mechanical damages, seizures, and Alzheimer's disease (Nykjaer et al., 2005; Underwood and Coulson, 2008). Among these pathophysiological processes, deficits on GABAergic neurotransmission in neurodegenerative and epileptic tissues have been reported (Sperk et al., 2004; Ben-Ari et al., 2007; Drexel et al., 2013). Interestingly, in our in vitro and ex vivo models, we found that accumulation of proBDNF in the extracellular space impaired GABAergic neurotransmission and induced upregulation of $\mathrm{p} 75^{\mathrm{NTR}}$. We hypothesize that this positive feedback mechanism operating between proBDNF and $\mathrm{p} 75^{\mathrm{NTR}}$ could be involved in the observed upregulation of $\mathrm{p} 75^{\mathrm{NTR}}$ in pathological conditions and neurodegenerative diseases (Zheng et al., 2010; Zeng et al., 2011; Shulga et al., 2012).

Our in vivo approach enabled us to investigate the consequences of endogenous accumulation of proBDNF. Thus, the expected outcomes are the demonstration that in vivo, a significant proportion of BDNF is secreted as a precursor, and that the extracellular proBDNF/mBDNF ratio modulates the strength of GABAergic synapses. Pathological alterations in BDNF processing have been reported in several cognitive dysfunctions in neurodevelopmental and neurodegenerative disorders (Barnes and Thomas, 2008; Unsain et al., 2008; Volosin et al., 2008; Carlino et al., 2011; Yang et al., 2011; Shulga et al., 2012). Because patients with cognitive disorders have abnormal GABA levels, it is plausible that alterations in BDNF processing produce a disturbance of GABAergic synaptic activity. This may then lead to an impaired neuronal network and may have an additive and/or multiplicative effect on neurological diseases.
In summary, our results provide evidence that the proBDNF/ p $75^{\text {NTR }}$ downstream signaling pathway inhibits the GABAergic system. In previous studies, it was shown that secreted BDNF at neuromuscular junctions can cause a stabilization or retraction of presynaptic terminals acting respectively on TrkB and $\mathrm{p} 75^{\mathrm{NTR}}$ (Yang et al., 2009; Je et al., 2012, 2013). Those authors suggest a model in which BDNF can be either the punishment or the reward signal, depending on the proteolytic conversion. Our results suggest that proBDNF released from the target cells might serve also as a reward or punishment signal for synaptic elimination in the CNS and consequently play a major role in shaping patterns of neuronal connections. These results are particularly interesting in light of the recent demonstration that endogenously expressed proBDNF regulates neuronal morphology and synaptic plasticity in hippocampus, effects that are distinct from those of mBDNF (Yang et al., 2014). This function of proBDNF in shaping neuronal connectivity is supported by the observation that regulated secretion of proBDNF can lead to either a TrkBdependent increase (Kuczewski et al., 2008b) or a p75 ${ }^{\text {NTR }}$ dependent decrease (Langlois et al., 2013) in GABAergic synapses in the developing hippocampus.

\section{References}

Balkowiec A, Katz DM (2002) Cellular mechanisms regulating activitydependent release of native brain-derived neurotrophic factor from hippocampal neurons. J Neurosci 22:10399-10407. Medline

Barnes P, Thomas KL (2008) Proteolysis of proBDNF is a key regulator in the formation of memory. PLoS One 3:e3248. CrossRef Medline

Ben-Ari Y, Gaiarsa JL, Tyzio R, Khazipov R (2007) GABA: a pioneer transmitter that excites immature neurons and generates primitive oscillations. Physiol Rev 87:1215-1284. CrossRef Medline

Bozdagi O, Rich E, Tronel S, Sadahiro M, Patterson K, Shapiro ML, Alberini CM, Huntley GW, Salton SR (2008) The neurotrophin-inducible gene $V g f$ regulates hippocampal function and behavior through a brainderived neurotrophic factor-dependent mechanism. J Neurosci 28:98579869. CrossRef Medline

Brandon NJ, Delmas P, Kittler JT, McDonald BJ, Sieghart W, Brown DA, Smart TG, Moss SJ (2000) GABAA receptor phosphorylation and functional modulation in cortical neurons by a protein kinase C-dependent pathway. J Biol Chem 275:38856-38862. CrossRef Medline

Buerli T, Pellegrino C, Baer K, Lardi-Studler B, Chudotvorova I, Fritschy JM, Medina I, Fuhrer C (2007) Efficient transfection of DNA or shRNA vectors into neurons using magnetofection. Nat Protoc 2:3090-3101. CrossRef Medline

Carlino D, Leone E, Di Cola F, Baj G, Marin R, Dinelli G, Tongiorgi E, De Vanna M (2011) Low serum truncated-BDNF isoform correlates with higher cognitive impairment in schizophrenia. J Psychiatr Res 45:273279. CrossRef Medline

Carrasco MA, Castro P, Sepulveda FJ, Tapia JC, Gatica K, Davis MI, Aguayo LG (2007) Regulation of glycinergic and GABAergic synaptogenesis by brain-derived neurotrophic factor in developing spinal neurons. Neuroscience 145:484-494. CrossRef Medline

Chih B, Engelman H, Scheiffele P (2005) Control of excitatory and inhibitory synapse formation by neuroligins. Science 307:1324-1328. CrossRef Medline

Colin-Le Brun I, Ferrand N, Caillard O, Tosetti P, Ben-Ari Y, Gaïarsa JL (2004) Spontaneous synaptic activity is required for the formation of functional GABAergic synapses in the developing rat hippocampus. J Physiol 559:129-139. CrossRef Medline

Drexel M, Kirchmair E, Sperk G (2013) Changes in the expression of GABAA receptor subunit mRNAs in parahippocampal areas after kainic acid induced seizures. Front Neural Circuits 7:142. Medline

Elmariah SB, Crumling MA, Parsons TD, Balice-Gordon RJ (2004) Postsynaptic TrkB-mediated signaling modulates excitatory and inhibitory neurotransmitter receptor clustering at hippocampal synapses. J Neurosci 24:2380-2393. CrossRef Medline

Elmariah SB, Oh EJ, Hughes EG, Balice-Gordon RJ (2005) Astrocytes regulate inhibitory synapse formation via Trk-mediated modulation of postsynaptic $\mathrm{GABA}_{\mathrm{A}}$ receptors. J Neurosci 25:3638-3650. CrossRef Medline 
Fiorentino H, Kuczewski N, Diabira D, Ferrand N, Pangalos MN, Porcher C, Gaiarsa JL (2009) $\mathrm{GABA}_{\mathrm{B}}$ receptor activation triggers BDNF release and promotes the maturation of GABAergic synapses. J Neurosci 29:1165011661. CrossRef Medline

Gehler S, Gallo G, Letourneau PC (2004) P75 neurotrophin receptor signaling regulates growth cone filopodial dynamics through modulating RhoA activity. J Neurosci 24:4363-4372. Medline

Ghosh A, Ginty DD, Bading H, Greenberg ME (1994) Calcium regulation of gene expression in neuronal cells. J Neurobiol 25:294-303. CrossRef Medline

Goffin D, Ali AB, Rampersaud N, Harkavyi A, Fuchs C, Whitton PS, Nairn AC, Jovanovic JN (2010) Dopamine-dependent tuning of striatal inhibitory synaptogenesis. J Neurosci 30:2935-2950. CrossRef Medline

Grabenstatter HL, Russek SJ, Brooks-Kayal AR (2012) Molecular pathways controlling inhibitory receptor expression. Epilepsia 53 [Suppl 9]:71-78. CrossRef Medline

Grabenstatter HL, Del Angel YC, Carlsen J, Wempe MF, White AM, Cogswell M, Russek SJ, Brooks-Kayal AR (2014) The effect of STAT3 inhibition on status epilepticus and subsequent spontaneous seizures in the pilocarpine model of acquired epilepsy. Neurobiol Dis 62:73-85. CrossRef Medline

Gubellini P, Ben-Ari Y, Gaïarsa JL (2005) Endogenous neurotrophins are required for the induction of GABAergic long-term potentiation in the neonatal rat hippocampus. J Neurosci 25:5796-5802. CrossRef Medline

Haubensak W, Narz F, Heumann R, Lessmann V (1998) BDNF-GFP containing secretory granules are localized in the vicinity of synaptic junctions of cultured cortical neurons. J Cell Sci 111: 1483-1493. Medline

Huang Z, Zang K, Reichardt LF (2005) The origin recognition core complex regulates dendrite and spine development in postmitotic neurons. J Cell Biol 170:527-535. CrossRef Medline

Hu Y, Lund IV, Gravielle MC, Farb DH, Brooks-Kayal AR, Russek SJ (2008) Surface expression of GABAA receptors is transcriptionally controlled by the interplay of cAMP-response element-binding protein and its binding partner inducible cAMP early repressor. J Biol Chem 283:9328-9340. CrossRef Medline

Jacob TC, Moss SJ, Jurd R (2008) GABA(A) receptor trafficking and its role in the dynamic modulation of neuronal inhibition. Nat Rev Neurosci 9:331-343. CrossRef Medline

Je HS, Yang F, Ji Y, Nagappan G, Hempstead BL, Lu B (2012) Role of probrain-derived neurotrophic factor (proBDNF) to mature BDNF conversion in activity-dependent competition at developing neuromuscular synapses. Proc Natl Acad Sci U S A 109:15924-15929. CrossRef Medline

Je HS, Yang F, Ji Y, Potluri S, Fu XQ, Luo ZG, Nagappan G, Chan JP, Hempstead B, Son YJ, Lu B (2013) ProBDNF and mature BDNF as punishment and reward signals for synapse elimination at mouse neuromuscular junctions. J Neurosci 33:9957-9962. CrossRef Medline

Joshi S, Kapur J (2009) Slow intracellular accumulation of GABA(A) receptor delta subunit is modulated by brain-derived neurotrophic factor. Neuroscience 164:507-519. CrossRef Medline

Jovanovic JN, Thomas P, Kittler JT, Smart TG, Moss SJ (2004) Brainderived neurotrophic factor modulates fast synaptic inhibition by regulating $\mathrm{GABA}_{\mathrm{A}}$ receptor phosphorylation, activity, and cell-surface stability. J Neurosci 24:522-530. CrossRef Medline

Kittler JT, Delmas P, Jovanovic JN, Brown DA, Smart TG, Moss SJ (2000) Constitutive endocytosis of $\mathrm{GABA}_{\mathrm{A}}$ receptors by an association with the adaptin AP2 complex modulates inhibitory synaptic currents in hippocampal neurons. J Neurosci 20:7972-7977. Medline

Kittler JT, Chen G, Honing S, Bogdanov Y, McAinsh K, Arancibia-Carcamo IL, Jovanovic JN, Pangalos MN, Haucke V, Yan Z, Moss SJ (2005) Phospho-dependent binding of the clathrin AP2 adaptor complex to GABAA receptors regulates the efficacy of inhibitory synaptic transmission. Proc Natl Acad Sci U S A 102:14871-14876. CrossRef Medline

Kittler JT, Chen G, Kukhtina V, Vahedi-Faridi A, Gu Z, Tretter V, Smith KR, McAinsh K, Arancibia-Carcamo IL, Saenger W, Haucke V, Yan Z, Moss SJ (2008) Regulation of synaptic inhibition by phospho-dependent binding of the AP2 complex to a YECL motif in the GABAA receptor gamma2 subunit. Proc Natl Acad Sci U S A 105:3616-3621. CrossRef Medline

Kuczewski N, Porcher C, Ferrand N, Fiorentino H, Pellegrino C, Kolarow R, Lessmann V, Medina I, Gaiarsa JL (2008a) Backpropagating action potentials trigger dendritic release of BDNF during spontaneous network activity. J Neurosci 28:7013-7023. CrossRef Medline

Kuczewski N, Langlois A, Fiorentino H, Bonnet S, Marissal T, Diabira D,
Ferrand N, Porcher C, Gaiarsa JL (2008b) Spontaneous glutamatergic activity induces a BDNF-dependent potentiation of GABAergic synapses in the newborn rat hippocampus. J Physiol 586:5119-5128. CrossRef Medline

Kuczewski N, Porcher C, Gaiarsa JL (2010) Activity-dependent dendritic secretion of brain-derived neurotrophic factor modulates synaptic plasticity. Eur J Neurosci 32:1239-1244. CrossRef Medline

Langlois A, Diabira D, Ferrand N, Porcher C, Gaiarsa JL (2013) NMDAdependent switch of proBDNF actions on developing GABAergic synapses. Cereb Cortex 23:1085-1096. CrossRef Medline

Lee R, Kermani P, Teng KK, Hempstead BL (2001) Regulation of cell survival by secreted proneurotrophins. Science 294:1945-1948. CrossRef Medline

Lessmann V, Brigadski T (2009) Mechanisms, locations, and kinetics of synaptic BDNF secretion: an update. Neurosci Res 65:11-22. CrossRef Medline

Li Z, Dong X, Dong X, Wang Z, Liu W, Deng N, Ding Y, Tang L, Hla T, Zeng R, Li L, Wu D (2005) Regulation of PTEN by Rho small GTPases. Nat Cell Biol 7:399-404. CrossRef Medline

Liu B, Li L, Zhang Q, Chang N, Wang D, Shan Y, Li L, Wang H, Feng H, Zhang L, Brann DW, Wan Q (2010) Preservation of GABAA receptor function by PTEN inhibition protects against neuronal death in ischemic. Stroke 41:1018-1026. CrossRef Medline

Logue SE, Martin SJ (2008) Caspase activation cascades in apoptosis. Biochem Soc Trans 36:1-9. CrossRef Medline

Lu B (2003) Pro-region of neurotrophins: role in synaptic modulation. Neuron 39:735-738. CrossRef Medline

Lu B, Pang PT, Woo NH (2005) The yin and yang of neurotrophin action. Nat Rev Neurosci 6:603-614. CrossRef Medline

Lund IV, Hu Y, Raol YH, Benham RS, Faris R, Russek SJ, Brooks-Kayal AR (2008) BDNF selectively regulates GABAA receptor transcription by activation of the JAK/STAT pathway. Sci Signal 1:ra9. CrossRef Medline

Luscher B, Fuchs T, Kilpatrick CL (2011) GABAA receptor traffickingmediated plasticity of inhibitory synapses. Neuron 70:385-409. CrossRef Medline

Maccario H, Perera NM, Davidson L, Downes CP, Leslie NR (2007) PTEN is destabilized by phosphorylation on Thr366. Biochem J 405:439-444. CrossRef Medline

Molina CA, Foulkes NS, Lalli E, Sassone-Corsi P (1993) Inducibility and negative autoregulation of CREM: an alternative promoter directs the expression of ICER, an early response repressor. Cell 75:875-886. CrossRef Medline

Mowla SJ, Farhadi HF, Pareek S, Atwal JK, Morris SJ, Seidah NG, Murphy RA (2001) Biosynthesis and post-translational processing of the precursor to brain-derived neurotrophic factor. J Biol Chem 276:12660-12666. CrossRef Medline

Nagappan G, Zaitsev E, Senatorov VV Jr, Yang J, Hempstead BL, Lu B (2009) Control of extracellular cleavage of ProBDNF by high frequency neuronal activity. Proc Natl Acad Sci U S A 106:1267-1272. CrossRef Medline

Nykjaer A, Willnow TE, Petersen CM (2005) p75 ${ }^{\text {NTR }}$ - Live or let die. Curr Opin Neurobiol 15:49-57. CrossRef Medline

Porcher C, Hatchett C, Longbottom RE, McAinch K, Sihra TS, Moss SJ, Thomson AM, Jovanovic JN (2011) Positive feedback regulation between gamma-aminobutyric acid type $\mathrm{A}(\mathrm{GABA}(\mathrm{A}))$ receptor signaling and brain-derived neurotrophic factor (BDNF) release in developing neurons. J Biol Chem 286:21667-21677. CrossRef Medline

Rico B, Xu B, Reichardt LF (2002) TrkB receptor signaling is required for establishment of GABAergic synapses in the cerebellum. Nat Neurosci 5:225-233. CrossRef Medline

Rudolph U, Knoflach F (2011) Beyond classical benzodiazepines: novel therapeutic potential of GABAA receptor subtypes. Nat Rev Drug Discov 10:685-697. CrossRef Medline

Shulga A, Magalhães AC, Autio H, Plantman S, di Lieto A, Nykjær A, Carlstedt T, Risling M, Arumäe U, Castrén E, Rivera C (2012) The loop diuretic bumetanide blocks posttraumatic p $75^{\mathrm{NTR}}$ upregulation and rescues injured neurons. J Neurosci 32:1757-1770. CrossRef Medline

Skolnick P (2012) Anxioselective anxiolytics: on a quest for the Holy Grail. Trends Pharmacol Sci 33:611-620. CrossRef Medline

Song W, Volosin M, Cragnolini AB, Hempstead BL, Friedman WJ (2010) ProNGF induces PTEN via p75 ${ }^{\text {NTR }}$ to suppress Trk-mediated survival signaling in brain neurons. J Neurosci 30:15608-15615. CrossRef Medline 
Sperk G, Furtinger S, Schwarzer C, Pirker S (2004) GABA and its receptors in epilepsy. Adv Exp Med Biol 548:92-103. CrossRef Medline

Swanwick CC, Murthy NR, Mtchedlishvili Z, Sieghart W, Kapur J (2006) Development of gamma-aminobutyric acidergic synapses in cultured hippocampal neurons. J Comp Neurol 495:497-510. CrossRef Medline

Tan KR, Rudolph U, Lüscher C (2011) Hooked on benzodiazepines: GABAA receptor subtypes and addiction. Trends Neurosci 34:188-197. CrossRef Medline

Thomas P, Mortensen M, Hosie AM, Smart TG (2005) Dynamic mobility of functional GABAA receptors at inhibitory synapses. Nat Neurosci 8:889897. CrossRef Medline

Twelvetrees AE, Yuen EY, Arancibia-Carcamo IL, MacAskill AF, Rostaing P, Lumb MJ, Humbert S, Triller A, Saudou F, Yan Z, Kittler JT (2010) Delivery of GABAARs to synapses is mediated by HAP1-KIF5 and disrupted by mutant huntingtin. Neuron 65:53-65. CrossRef Medline

Underwood CK, Coulson EJ (2008) The p75 neurotrophin receptor. Int J Biochem Cell Biol 40:1664-1668. CrossRef Medline

Unsain N, Nuñez N, Anastasía A, Mascó DH (2008) Status epilepticus induces a TrkB to p75 neurotrophin receptor switch and increases brainderived neurotrophic factor interaction with p 75 neurotrophin receptor: an initial event in neuronal injury induction. Neuroscience 154:978-993. CrossRef Medline

Vasudevan NT, Mohan ML, Gupta MK, Hussain AK, Naga Prasad SV (2011) Inhibition of protein phosphatase $2 \mathrm{~A}$ activity by $\mathrm{PI} 3 \mathrm{~K} \gamma$ regulates $\beta$-adrenergic receptor function. Mol Cell 41:636-648. CrossRef Medline

Vazquez F, Ramaswamy S, Nakamura N, Sellers WR (2000) Phosphorylation of the PTEN tail regulates protein stability and function. Mol Cell Biol 20:5010-5018. CrossRef Medline

Volosin M, Trotter C, Cragnolini A, Kenchappa RS, Light M, Hempstead BL, Carter BD, Friedman WJ (2008) Induction of proneurotrophins and activation of $\mathrm{p} 75^{\mathrm{NTR}}$-mediated apoptosis via neurotrophin receptorinteracting factor in hippocampal neurons after seizures. J Neurosci 28 : 9870-9879. CrossRef Medline

Weber T, Zemelman BV, McNew JA, Westermann B, Gmachl M, Parlati F, Söllner TH, Rothman JE (1998) SNAREpins: minimal machinery for membrane fusion. Cell 92:759-772. CrossRef Medline

Winsky-Sommerer R (2009) Role of GABAA receptors in the physiology and pharmacology of sleep. Eur J Neurosci 29:1779-1794. CrossRef Medline

Wu YJ, Krüttgen A, Möller JC, Shine D, Chan JR, Shooter EM, Cosgaya JM
(2004) Nerve growth factor, brain-derived neurotrophic factor, and neurotrophin-3 are sorted to dense-core vesicles and released via the regulated pathway in primary rat cortical neurons. J Neurosci Res 75:825834. CrossRef Medline

Yamashita T, Tohyama M (2003) The p75 receptor acts as a displacement factor that releases Rho from Rho-GDI. Nat Neurosci 6:461-467. Medline

Yang J, Siao CJ, Nagappan G, Marinic T, Jing D, McGrath K, Chen ZY, Mark W, Tessarollo L, Lee FS, Lee FS, Lu B, Hempstead BL (2009) Neuronal release of proBDNF. Nat Neurosci 12:113-115. CrossRef Medline

Yang J, Harte-Hargrove LC, Siao CJ, Marinic T, Clarke R, Ma Q, Jing D, Lafrancois JJ, Bath KG, Mark W, Ballon D, Lee FS, Scharfman HE, Hempstead BL (2014) proBDNF negatively regulates neuronal remodeling, synaptic transmission, and synaptic plasticity in hippocampus. Cell Rep 7:796-806. CrossRef Medline

Yang M, Lim Y, Li X, Zhong JH, Zhou XF (2011) Precursor of brain-derived neurotrophic factor (proBDNF) forms a complex with Huntingtinassociated protein-1 (HAP1) and sortilin that modulates proBDNF trafficking, degradation, and processing. J Biol Chem 286:16272-16284. CrossRef Medline

Yu W, Jiang M, Miralles CP, Li RW, Chen G, de Blas AL (2007) Gephyrin clustering is required for the stability of GABAergic synapses. Mol Cell Neurosci 36:484-500. CrossRef Medline

Zeng F, Lu JJ, Zhou XF, Wang YJ (2011) Roles of p75 ${ }^{\text {NTR }}$ in the pathogenesis of Alzheimer's disease: a novel therapeutic target. Biochem Pharmacol 82:1500-1509. CrossRef Medline

Zhang X, Odom DT, Koo SH, Conkright MD, Canettieri G, Best J, Chen H, Jenner R, Herbolsheimer E, Jacobsen E, Kadam S, Ecker JR, Emerson B, Hogenesch JB, Unterman T, Young RA, Montminy M (2005) Genomewide analysis of cAMP-response element binding protein occupancy, phosphorylation, and target gene activation in human tissues. Proc Natl Acad Sci U S A 102:4459-4464. CrossRef Medline

Zheng Z, Sabirzhanov B, Keifer J (2010) Oligomeric amyloid-\{beta\} inhibits the proteolytic conversion of brain-derived neurotrophic factor (BDNF), AMPA receptor trafficking, and classical conditioning. J Biol Chem 285: 34708-34717. CrossRef Medline

Zhou XF, Song XY, Zhong JH, Barati S, Zhou FH, Johnson SM (2004) Distribution and localization of pro-brain-derived neurotrophic factor-like immunoreactivity in the peripheral and central nervous system of the adult rat. J Neurochem 91:704-715. CrossRef Medline 